\title{
Roles of miRNAs in Early Embryonic Development of Drosophila melanogaster
}

\section{Shigeru Takasaki*}

Toyo University 1-1-1 Izumino Itakura-machi, Ora-gun Gunma 374-0193, Japan

\begin{abstract}
MicroRNAs (miRNAs) are small ( 24 nucleotides) noncoding RNA molecules thought to play an important role in regulating gene expression. Although knowledge of the biological functions of most miRNAs is still limited, miRNAs are thought to regulate the gene expressions in embryo development. Since cis-regulatory elements regulate the gene expression in the early embryonic development of Drosophila melanogaster, this paper analyzes the relations between the nucleotide sequences of $D$. melanogaster miRNAs and cis-regulatory elements $b c d, h b$, eve, $K r$, and $g t$ genes. Finding from consensus sequences that individual miRNAs are closely related to the 5 ' upstream regions of these genes, the paper proposes that miRNA mediates inquiries and responses in regulatory interactions between genes. This paper also analyzes the relations between the frequency probabilities of miRNA consensus sequences and random sequences in the 5' upstream regions of the target genes and shows that the probabilities of consistencies between individual miRNAs and 5' upstream regions are greater than those expected for same-length sequences with random nucleotide frequencies. These results thus imply that some miRNAs are closely related to the 5' upstream regions of certain genes and play important roles in the regulation of gene expression during the embryonic development of $D$. melanogaster.
\end{abstract}

Keywords: MicroRNAs; Gene expression; Cis-regulatory elements; Embryo development; Gene regulation; Drosophila melanogaster

\section{Introduction}

MicroRNAs (miRNAs) are small ( 24 nucleotides) noncoding RNA molecules that regulate gene expression post-transcriptionally by basepairing to mRNAs [1-4]. Many miRNAs have recently been identified in various multicellular organisms and are evolutionally conserved. The knowledge of biological functions of most miRNAs is still limited, but these molecules are expected to regulate the gene expression at various biological stages. They are thought, for example, to play an important role in embryo development. The miRNA lin-4 first identified in the nematode Caenorhabdis elegans regulates the lin-14 genes and as a result controls the developmental timing. Another miRNA, let-7, is also involved in developmental timing in C. elegans $[5,6]$. Although many animal miRNAs are known, the biological functions of only a few are understood [7-17].

Important roles in gene expression are also played by cisregulatory elements. In the early embryonic development of Drosophila melanogaster, for example, the expression of the hunchback $(h b)$ gene is regulated by bicoid protein $(\mathrm{Bcd})$ cis-regulatory elements [18-20]. The detailed molecular mechanisms of cis-regulatory elements, however, are still unknown [21-26].

Although miRNAs and cis-regulatory elements have been thought to have different binding regions in the target mRNAs-those for miRNAs are in the 3' untranslated regions (3' UTRs), whereas those for cis-regulatory elements are in the promoter regions [27] - from the viewpoint of gene regulation there is no clear reason for their binding to these regions. As the cis-regulatory elements and miRNAs can be considered trans-acting factors [28], miRNAs might also be able to regulate gene expression by binding to promoter regions of target genes. This paper therefore analyzes the relations between miRNAs and cis-regulatory elements by examining gene expressions in the early embryonic development of $D$. melanogaster-especially the relations between miRNAs and $b c d, h b$, even-skipped (eve), Krüppel $(K r)$, and giant $(g t)$ - and obtains consensus sequences indicating that individual miRNAs are closely related to the 5' upstream regions of these genes.

The paper therefore proposes that miRNAs mediate inquiry/ response regulations between genes. For example, miRNAs might help cis-regulatory elements bind to the 5 ' upstream region of the gene $h b$ by carrying inquiries and responses between the genes $b c d$ and $h b$. Such roles can be supported by the miRNA consensus sequences in the $5^{\prime}$ upstream regions of the target genes. The paper also analyzes the relations between the frequency probabilities of the miRNA consensus sequences and random sequences in the 5' upstream regions of the target genes. The results indicate that the probabilities of consistencies between individual miRNAs and the 5' upstream regions of target genes are greater than would be expected for same-length sequences with random nucleotide frequencies. This implies that some miRNAs are closely related to the $5^{\prime}$ upstream regions of certain genes and help regulate gene expression in the embryonic development of D. melanogaster.

\section{Materials and Methods}

\section{miRBase}

The following analysis used miRBase, which provides integrated interfaces to comprehensive microRNA sequence data, annotations and predicted gene targets $[29,30]$. It was used for searching target miRNAs of individual genes and for searching target genes of individual miRNAs. It was also used for searching sequences of individual miRNAs.

\section{RSAT}

Regulatory Sequence Analysis Tools (RSAT) provides a series of molecular computer programs designed for detecting regulatory signals in noncoding sequences [31]. The following analysis used RSAT to search individual miRNAs and the 5' upstream regions of the related genes for consensus sequences.

*Corresponding author: Shigeru Takasaki, Toyo University 1-1-1 Izumino Itakuramachi, Ora-gun Gunma 374-0193 Japan, Tel: +81-276-82-9024; Fax: +81-276-829033; E-mail: s_takasaki@toyo.jp

Received November 25, 2013; Accepted December 17, 2013; Published December 19, 2013

Citation: Takasaki S (2013) Roles of miRNAs in Early Embryonic Development of Drosophila melanogaster. Genetics 2: 122. doi:10.4172/2161-1041.1000122

Copyright: ( 2013 Takasaki S. This is an open-access article distributed under the terms of the Creative Commons Attribution License, which permits unrestricted use, distribution, and reproduction in any medium, provided the original author and source are credited. 
Citation: Takasaki S (2013) Roles of miRNAs in Early Embryonic Development of Drosophila melanogaster. Genetics 2: 122. doi:10.4172/21611041.1000122

Page 2 of 14

\section{Drosophila DNase I footprint database}

Drosophila DNase I footprint database provides a systematic annotation of transcription factor binding sites in the fruit fly Drosophila melanogaster [32]. It was used to search cis-regulatory sequences for the genes of $D$. melanogaster.

\section{Results and Discussion}

\section{Relations between cis-regulatory elements and individual miRNAs for $b c d$ and $h b$}

Driever and Nusslen Volhard [18] reported that $h b$ gene expression was activated by the binding of $b c d$ protein $(\mathrm{Bcd})$ to the 5 ' noncoding region upstream of the gene $h b$ as shown in Figure 1. They found that $h b$ gene expression was activated when the concentration of Bcd bound to $h b$ became higher than a threshold level. The consensus sequences of the Bcd cis-regulatory element were reported to be "TCTAATCCC" or

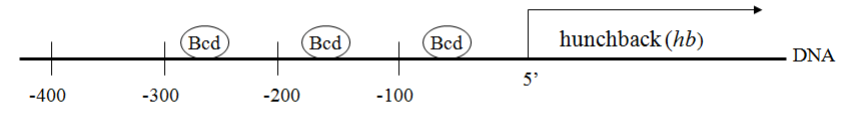

Figure 1: Bcd binding sites in the 5' upstream region of the gene $h b$.
"CGTAATCCC" [18-20]. As the $h b$ gene expression is activated when a sufficient amount of $\mathrm{Bcd}$ is bound to the $h b 5$ ' noncoding region, this cis-regulatory element plays an important role in the development of the anterior-posterior axis of the embryo.

The miRNAs of genes $b c d$ and $h b$ can be obtained from miRBase (Materials and Methods). For simplicity, they are expressed as the cDNA sequences (5' to 3') listed in Table 1. Although miRNAs have generally been thought to regulate post-transcriptional gene activity by binding to specific sequences in the 3' UTRs of target mRNAs, other possible binding regions should be considered. As cis-regulatory elements bound to 5' upstream regions (promoters) of target genes regulate the gene expression, the 5' noncoding regions can be considered areas important for gene regulations. If miRNAs of the gene $b c d$ were related to the regulation of the expression of the gene $h b$, they might be expected to bind to the 5 ' noncoding regions of the $h b$ gene. Conversely, if miRNAs of the gene $h b$ were bound to the 5 ' noncoding regions of the gene $b c d$, they might control the $b c d$. That is, if these miRNAs were bound to the promoters of both genes, they could be play roles in the regulations of both genes.

One way to evaluate this possibility is to search the miRNAs and the $5^{\prime}$ upstream regions of both genes for consensus sequences. These sequences can be obtained by using RSAT (see Materials and Methods) and are listed in Tables $2 a$ and $2 b$. It is clear from Table 2a that there

sequence (cDNA 5' to $3^{\prime}$ )

\begin{tabular}{|c|c|c|c|c|c|c|c|c|c|c|c|c|c|c|c|c|c|c|c|c|c|c|c|c|c|}
\hline gene & miRNA & 1 & 2 & 3 & 4 & 5 & 6 & 7 & 8 & 9 & 10 & 11 & 12 & 13 & 14 & 15 & 16 & 17 & 18 & 19 & 20 & 21 & 22 & 23 & 24 \\
\hline \multirow{11}{*}{$b c d$} & dme-miR-79 & $\mathrm{T}$ & A & A & A & G & C & $\mathrm{T}$ & A & G & A & $\mathrm{T}$ & $\mathrm{T}$ & A & C & C & A & A & A & G & C & A & $\mathrm{T}$ & & \\
\hline & dme-miR-4 & A & $\mathrm{T}$ & A & A & A & G & C & $\mathrm{T}$ & A & G & A & C & A & A & C & C & A & $\mathrm{T}$ & $\mathrm{T}$ & G & A & & & \\
\hline & dme-miR-286 & $\mathrm{T}$ & G & A & C & $\mathrm{T}$ & A & G & A & C & C & G & A & A & C & A & C & $\mathrm{T}$ & C & G & $\mathrm{T}$ & G & C & $\mathrm{T}$ & \\
\hline & dme-miR-279 & $\mathrm{T}$ & $G$ & A & $\mathrm{C}$ & $\mathrm{T}$ & A & G & A & $\mathrm{T}$ & C & C & A & $\mathrm{C}$ & A & $\mathrm{C}$ & $\mathrm{T}$ & C & A & $\mathrm{T}$ & $\mathrm{T}$ & A & A & & \\
\hline & dme-miR-996 & $\mathrm{T}$ & G & A & $\mathrm{C}$ & $\mathrm{T}$ & A & G & A & $\mathrm{T}$ & $\mathrm{T}$ & $\mathrm{T}$ & C & A & $\mathrm{T}$ & G & C & $\mathrm{T}$ & C & G & $\mathrm{T}$ & C & $\mathrm{T}$ & & \\
\hline & dme-miR-999 & $\mathrm{T}$ & G & $\mathrm{T}$ & $\mathrm{T}$ & A & A & C & $\mathrm{T}$ & G & $\mathrm{T}$ & A & A & G & A & $\mathrm{C}$ & $\mathrm{T}$ & G & $\mathrm{T}$ & G & $\mathrm{T}$ & $\mathrm{C}$ & $\mathrm{T}$ & & \\
\hline & dme-miR-315 & $\mathrm{T}$ & $\mathrm{T}$ & $\mathrm{T}$ & $\mathrm{T}$ & G & A & $\mathrm{T}$ & $\mathrm{T}$ & G & $\mathrm{T}$ & $\mathrm{T}$ & G & $\mathrm{C}$ & $\mathrm{T}$ & C & A & G & A & A & A & $\mathrm{G}$ & $\mathrm{C}$ & & \\
\hline & dme-miR-1000 & A & $\mathrm{T}$ & A & $\mathrm{T}$ & $\mathrm{T}$ & G & $\mathrm{T}$ & C & C & $\mathrm{T}$ & G & $\mathrm{T}$ & $\mathrm{C}$ & A & C & A & G & C & A & G & $\mathrm{T}$ & & & \\
\hline & dme-miR-283 & $\mathrm{T}$ & A & A & A & $\mathrm{T}$ & A & $\mathrm{T}$ & C & A & G & C & $\mathrm{T}$ & G & G & $\mathrm{T}$ & A & A & $\mathrm{T}$ & $\mathrm{T}$ & C & $\mathrm{T}$ & & & \\
\hline & dme-miR-989 & $\mathrm{T}$ & G & $\mathrm{T}$ & G & A & $\mathrm{T}$ & G & $\mathrm{T}$ & G & A & $\mathrm{C}$ & G & $\mathrm{T}$ & A & G & $\mathrm{T}$ & G & G & A & A & $\mathrm{C}$ & & & \\
\hline & dme-miR-1017 & G & A & A & A & G & C & $\mathrm{T}$ & C & $\mathrm{T}$ & A & C & C & $\mathrm{C}$ & A & A & A & C & $\mathrm{T}$ & C & A & $\mathrm{T}$ & C & C & \\
\hline \multirow{6}{*}{$h b$} & dme-miR-989 & $\mathrm{T}$ & G & $\mathrm{T}$ & G & A & $\mathrm{T}$ & G & $\mathrm{T}$ & G & A & C & G & $\mathrm{T}$ & A & G & $\mathrm{T}$ & G & G & A & A & C & & & \\
\hline & dme-miR-963 & A & C & A & A & G & G & $\mathrm{T}$ & A & A & A & $\mathrm{T}$ & A & $\mathrm{T}$ & C & A & G & G & $\mathrm{T}$ & $\mathrm{T}$ & G & $\mathrm{T}$ & $\mathrm{T}$ & $\mathrm{T}$ & C \\
\hline & dme-miR-927 & $\mathrm{T}$ & $\mathrm{T}$ & $\mathrm{T}$ & A & G & A & A & $\mathrm{T}$ & $\mathrm{T}$ & C & C & $\mathrm{T}$ & A & C & $\mathrm{G}$ & $\mathrm{C}$ & $\mathrm{T}$ & $\mathrm{T}$ & $\mathrm{T}$ & A & $\mathrm{C}$ & C & & \\
\hline & dme-miR-8 & $\mathrm{T}$ & A & A & $\mathrm{T}$ & A & C & $\mathrm{T}$ & G & $\mathrm{T}$ & C & A & G & $\mathrm{G}$ & $\mathrm{T}$ & A & A & A & G & A & $\mathrm{T}$ & $\mathrm{G}$ & $\mathrm{T}$ & C & \\
\hline & dme-miR-315 & $\mathrm{T}$ & $\mathrm{T}$ & $\mathrm{T}$ & $\mathrm{T}$ & G & A & $\mathrm{T}$ & $\mathrm{T}$ & G & $\mathrm{T}$ & $\mathrm{T}$ & G & $C$ & $\mathrm{~T}$ & $C$ & A & G & A & A & A & $\mathrm{G}$ & C & & \\
\hline & dme-miR-976 & $\mathrm{T}$ & $\mathrm{T}$ & G & G & A & $\mathrm{T}$ & $\mathrm{T}$ & A & G & $\mathrm{T}$ & $\mathrm{T}$ & A & $\mathrm{T}$ & C & A & $\mathrm{T}$ & C & A & A & $\mathrm{T}$ & $\mathrm{G}$ & C & & \\
\hline eve & dme-miR-315 & $\mathrm{T}$ & $\mathrm{T}$ & $\mathrm{T}$ & $\mathrm{T}$ & G & A & $\mathrm{T}$ & $\mathrm{T}$ & G & $\mathrm{T}$ & $\mathrm{T}$ & G & $\mathrm{C}$ & $\mathrm{T}$ & C & A & G & A & A & A & G & C & & \\
\hline \multirow{9}{*}{$K r$} & dme-miR-277 & $\mathrm{T}$ & A & A & A & $\mathrm{T}$ & G & C & A & C & $\mathrm{T}$ & A & $\mathrm{T}$ & $\mathrm{C}$ & $\mathrm{T}$ & G & G & $\mathrm{T}$ & A & C & G & A & C & A & \\
\hline & dme-miR-274 & $\mathrm{T}$ & $\mathrm{T}$ & $\mathrm{T}$ & $\mathrm{T}$ & G & $\mathrm{T}$ & G & A & C & C & G & A & $C$ & A & C & $\mathrm{T}$ & A & A & C & G & $G$ & G & $\mathrm{T}$ & A \\
\hline & dme-miR-305 & A & $\mathrm{T}$ & $\mathrm{T}$ & G & $\mathrm{T}$ & A & C & $\mathrm{T}$ & $\mathrm{T}$ & C & A & $\mathrm{T}$ & $\mathrm{C}$ & A & G & G & $\mathrm{T}$ & G & C & $\mathrm{T}$ & C & $\mathrm{T}$ & G & \\
\hline & dme-miR-315 & $\mathrm{T}$ & $\mathrm{T}$ & $\mathrm{T}$ & $\mathrm{T}$ & G & A & $\mathrm{T}$ & $\mathrm{T}$ & G & $\mathrm{T}$ & $\mathrm{T}$ & G & C & $\mathrm{T}$ & C & A & G & A & A & A & G & C & & \\
\hline & dme-miR-962 & A & $\mathrm{T}$ & A & A & G & G & $\mathrm{T}$ & A & G & A & G & A & A & A & $\mathrm{T}$ & $\mathrm{T}$ & G & A & $\mathrm{T}$ & G & C & $\mathrm{T}$ & G & $\mathrm{T}$ \\
\hline & dme-miR-263b & C & $\mathrm{T}$ & $\mathrm{T}$ & G & G & C & A & C & $\mathrm{T}$ & G & G & G & A & G & A & A & $\mathrm{T}$ & $\mathrm{T}$ & C & A & C & & & \\
\hline & dme-miR-316 & $\mathrm{T}$ & G & $\mathrm{T}$ & $\mathrm{C}$ & $\mathrm{T}$ & $\mathrm{T}$ & $\mathrm{T}$ & $\mathrm{T}$ & $\mathrm{T}$ & $\mathrm{C}$ & $\mathrm{C}$ & G & $\mathrm{C}$ & $\mathrm{T}$ & $T$ & A & C & $\mathrm{T}$ & G & G & $\mathrm{C}$ & G & & \\
\hline & dme-miR-1011 & $\mathrm{T}$ & $\mathrm{T}$ & A & $\mathrm{T}$ & $\mathrm{T}$ & G & G & $\mathrm{T}$ & $\mathrm{T}$ & C & A & A & A & $\mathrm{T}$ & $\mathrm{C}$ & G & C & $\mathrm{T}$ & C & G & $\mathrm{C}$ & A & G & \\
\hline & dme-miR-283 & $\mathrm{T}$ & A & A & A & $\mathrm{T}$ & A & $\mathrm{T}$ & $\mathrm{C}$ & A & G & C & $\mathrm{T}$ & G & G & $\mathrm{T}$ & A & A & $\mathrm{T}$ & $\mathrm{T}$ & C & $\mathrm{T}$ & & & \\
\hline \multirow{5}{*}{$g t$} & dme-miR-iab-4-5p & A & $\mathrm{C}$ & G & $\mathrm{T}$ & A & $\mathrm{T}$ & A & $\mathrm{C}$ & $\mathrm{T}$ & G & A & A & $\mathrm{T}$ & G & $\mathrm{T}$ & A & $\mathrm{T}$ & C & C & $\mathrm{T}$ & $\mathrm{G}$ & A & & \\
\hline & dme-miR-999 & $\mathrm{T}$ & G & $\mathrm{T}$ & $\mathrm{T}$ & A & A & C & $\mathrm{T}$ & G & $\mathrm{T}$ & A & A & G & A & C & $\mathrm{T}$ & G & $\mathrm{T}$ & G & $\mathrm{T}$ & C & $\mathrm{T}$ & & \\
\hline & dme-miR-1014 & A & A & A & A & $\mathrm{T}$ & $\mathrm{T}$ & C & A & $\mathrm{T}$ & $\mathrm{T}$ & $\mathrm{T}$ & $\mathrm{T}$ & $C$ & A & $\mathrm{T}$ & $\mathrm{T}$ & $\mathrm{T}$ & G & C & A & $\mathrm{G}$ & & & \\
\hline & dme-miR-1006 & $\mathrm{T}$ & A & A & A & $\mathrm{T}$ & $\mathrm{T}$ & C & G & A & $\mathrm{T}$ & $\mathrm{T}$ & $\mathrm{T}$ & $C$ & $\mathrm{~T}$ & $\mathrm{~T}$ & A & $\mathrm{T}$ & $\mathrm{T}$ & C & A & $\mathrm{T}$ & A & G & \\
\hline & dme-miR-10-3p & C & A & A & A & $\mathrm{T}$ & $\mathrm{T}$ & C & G & G & $\mathrm{T}$ & $\mathrm{T}$ & $\mathrm{T}$ & $\mathrm{C}$ & $\mathrm{T}$ & A & G & A & G & A & G & G & $\mathrm{T}$ & $\mathrm{T}$ & $\mathrm{T}$ \\
\hline
\end{tabular}

Table 1: Relations between individual genes and their miRNAs. 
Citation: Takasaki S (2013) Roles of miRNAs in Early Embryonic Development of Drosophila melanogaster. Genetics 2: 122. doi:10.4172/21611041.1000122

Page 3 of 14

are many sequences common to the miRNAs of the bcd gene and the 5' upstream regions of the $h b$ gene. The sequence "AAAGCT" of dme-miR-79, for example, is consistent with the sequence from -4333 to -4328 of the 5 upstream region of $h b$. Similarly, the sequence "TGTTAACT" of dme-miR-999 is consistent with the sequence from -4308 to -4315 of the 5 ' upstream region of $h b$.

\begin{tabular}{|c|c|c|c|c|c|c|c|c|c|c|c|c|c|c|c|c|c|c|c|c|c|c|c|c|c|c|}
\hline gene & miRNA/5'region & 1 & 2 & 3 & 4 & 5 & 6 & 7 & 8 & 9 & 10 & 11 & 12 & 13 & 14 & 15 & 16 & 17 & 18 & 19 & 20 & 21 & 22 & 23 & 24 & 25 \\
\hline$b c d$ & dme-miR-79 & $\mathrm{T}$ & A & A & A & G & C & $\begin{array}{ll}\mathrm{T} \\
\mathrm{l}\end{array}$ & A & G & A & $\mathrm{T}$ & T & A & C & C & A & A & A & G & C & A & $\mathrm{T}$ & & & \\
\hline \multirow{11}{*}{$h b$} & $5^{\prime}(-4333) F$ & C & A & A & A & G & C & T & $T$ & $T$ & G & C & C & C & A & A & A & $\mathrm{T}$ & T & A & A & G & $\mathrm{T}$ & & & \\
\hline & coincidence & & $\circ$ & $\circ$ & $\circ$ & $\circ$ & $\circ$ & $\circ$ & & & & & & & & & $\circ$ & & & & & & $\circ$ & & & \\
\hline & & & & & & & & & & & & & & & & & & & & & & & & & & \\
\hline & $5^{\prime}(-3078) F$ & A & A & A & A & G & C & T & $\mathrm{T}$ & $\mathrm{T}$ & C & C & G & C & G & G & A & $\mathrm{T}$ & A & A & A & C & A & & & \\
\hline & coincidence & & $\circ$ & $\circ$ & $\circ$ & $\circ$ & $\circ$ & $\circ$ & & & & & & & & & $\circ$ & & $\circ$ & & & & & & & \\
\hline & & & & & & & & & & & & & & & & & & & & & & & & & & \\
\hline & $5^{\prime}(-4326) R$ & C & A & A & A & G & C & T & $\mathrm{T}$ & $\mathrm{T}$ & G & C & C & A & C & A & A & $\mathrm{T}$ & T & A & G & C & A & & & \\
\hline & coincidence & & $\circ$ & $\circ$ & $\circ$ & $\circ$ & $\circ$ & $\circ$ & & & & & & $\circ$ & $\circ$ & & $\circ$ & & & & & & & & & \\
\hline & & & & & & & & & & & & & & & & & & & & & & & & & & \\
\hline & $5^{\prime}(-3071) R$ & G & A & A & A & G & C & $\mathrm{T}$ & $\mathrm{T}$ & $\mathrm{T}$ & $\mathrm{T}$ & G & C & G & A & A & $\mathrm{T}$ & $\mathrm{T}$ & T & C & $\mathrm{T}$ & A & C & & & \\
\hline & coincidence & & $\circ$ & $\circ$ & $\circ$ & $\circ$ & $\circ$ & $\circ$ & & & & & & & & & & & & & & & & & & \\
\hline & & & & & & & & & & & & & & & & & & & & & & & & & & \\
\hline$b c d$ & dme-miR-4 & A & $T$ & A & A & A & G & C & $T$ & A & $G$ & A & C & A & A & C & $\mathrm{C}$ & A & $T$ & $\mathrm{~T}$ & G & $\mathrm{A}$ & & & & \\
\hline \multirow[t]{2}{*}{$h b$} & $5^{\prime}(-4284) F$ & $\mathrm{~T}$ & $\mathrm{~T}$ & A & A & A & G & C & A & A & $\mathrm{C}$ & A & A & $G$ & $\mathrm{G}$ & A & A & $T$ & C & $\mathrm{T}$ & $\mathrm{C}$ & C & & & & \\
\hline & coincidence & & $\circ$ & $\circ$ & $\circ$ & $\circ$ & $\circ$ & $\circ$ & & $\circ$ & & $\circ$ & & & & & & & & $\circ$ & & & & & & \\
\hline & & & & & & & & & & & & & & & & & & & & & & & & & & \\
\hline$b c d$ & dme-miR-286 & $\mathrm{T}$ & G & A & C & $T$ & A & G & A & C & $\mathrm{C}$ & $G$ & A & A & $\mathrm{C}$ & A & $\mathrm{C}$ & $\mathrm{T}$ & C & G & $\mathrm{T}$ & G & $\mathrm{C}$ & $\mathrm{T}$ & & \\
\hline \multirow[t]{2}{*}{$h b$} & $5^{\prime}(-1576) F$ & $\mathrm{C}$ & G & $\mathrm{A}$ & C & $T$ & A & G & C & A & $\mathrm{C}$ & A & $T$ & $G$ & $T$ & $T$ & $T$ & A & G & $T$ & $T$ & $T$ & A & $C$ & & \\
\hline & coincidence & & $\circ$ & $\circ$ & $\circ$ & $\circ$ & $\circ$ & $\circ$ & & & $\circ$ & & & & & & & & & & $\circ$ & & & & & \\
\hline & & & & & & & & & & & & & & & & & & & & & & & & & & \\
\hline$b c d$ & dme-miR-279 & $\mathrm{T}$ & G & A & C & $T$ & A & G & A & $T$ & $C$ & $C$ & A & $C$ & $A$ & C & $T$ & C & A & $\mathrm{T}$ & $\mathrm{T}$ & A & A & & & \\
\hline \multirow[t]{2}{*}{$h b$} & $5^{\prime}(-1576) \mathrm{F}$ & C & G & A & C & $\mathrm{T}$ & A & G & $C$ & A & C & A & $T$ & $G$ & $T$ & $T$ & $\mathrm{~T}$ & A & G & $\mathrm{T}$ & $\mathrm{T}$ & $T$ & A & & & \\
\hline & coincidence & & $\circ$ & $\circ$ & $\circ$ & $\circ$ & $\circ$ & $\circ$ & & & $\circ$ & & & & & & $\circ$ & & & $\circ$ & $\circ$ & & $\circ$ & & & \\
\hline & & & & & & & & & & & & & & & & & & & & & & & & & & \\
\hline$b c d$ & dme-miR-996 & $\mathrm{T}$ & G & A & C & $\mathrm{T}$ & A & G & A & $T$ & $\mathrm{~T}$ & T & C & A & $\mathrm{T}$ & $\mathrm{G}$ & $C$ & $T$ & C & G & $\mathrm{T}$ & C & $\mathrm{T}$ & & & \\
\hline \multirow[t]{2}{*}{$h b$} & $5^{\prime}(-1576) \mathrm{F}$ & C & G & A & C & $T$ & A & G & $C$ & A & $C$ & A & $T$ & $G$ & $T$ & $T$ & $T$ & A & G & $T$ & $T$ & $\mathrm{~T}$ & A & & & \\
\hline & coincidence & & $\circ$ & $\circ$ & $\circ$ & $\circ$ & $\circ$ & $\circ$ & & & & & & & $\circ$ & & & & & & $\circ$ & & & & & \\
\hline & & & & & & & & & & & & & & & & & & & & & & & & & & \\
\hline$b c d$ & dme-miR-999 & $T$ & G & $\mathrm{T}$ & $T$ & A & A & C & $T$ & $\mathrm{G}$ & $T$ & A & A & $G$ & A & $C$ & $T$ & $G$ & $T$ & $G$ & $T$ & G & $T$ & $\mathrm{C}$ & $\mathrm{T}$ & \\
\hline \multirow[t]{2}{*}{$h b$} & $5^{\prime}(-4308) R$ & $\mathrm{~T}$ & G & $\mathrm{T}$ & $T$ & A & A & C & $T$ & $\mathrm{~T}$ & A & A & $T$ & $\mathrm{~T}$ & $\mathrm{~T}$ & G & G & $\mathrm{G}$ & C & A & A & A & G & $\mathrm{C}$ & $\mathrm{T}$ & \\
\hline & coincidence & $\circ$ & $\circ$ & $\circ$ & $\circ$ & $\circ$ & $\circ$ & $\circ$ & $\circ$ & & & $\circ$ & & & & & & $\circ$ & & & & & & $\circ$ & $\circ$ & \\
\hline & & & & & & & & & & & & & & & & & & & & & & & & & & \\
\hline$b c d$ & dme-miR-315 & $\mathrm{T}$ & $\mathrm{T}$ & $\mathrm{T}$ & $\begin{array}{l}\mathrm{T} \\
\end{array}$ & G & A & $\begin{array}{ll}\mathrm{T} \\
\end{array}$ & $T$ & G & $\mathrm{T}$ & $\mathrm{T}$ & G & C & $\mathrm{T}$ & C & A & G & A & A & A & G & C & & & \\
\hline \multirow[t]{2}{*}{$h b$} & $5^{\prime}(-961) R$ & C & $\mathrm{T}$ & $\mathrm{T}$ & $\mathrm{T}$ & G & A & $\mathrm{T}$ & $\mathrm{T}$ & $\mathrm{T}$ & $G$ & C & G & $\mathrm{T}$ & $A$ & $\mathrm{G}$ & $\mathrm{T}$ & $\mathrm{T}$ & $T$ & $\mathrm{~T}$ & $T$ & C & $T$ & & & \\
\hline & coincidence & & $\circ$ & $\circ$ & $\circ$ & 0 & $\circ$ & $\circ$ & $\circ$ & & & & $\circ$ & & & & & & & & & & & & & \\
\hline & & & & & & & & & & & & & & & & & & & & & & & & & & \\
\hline \multirow[t]{2}{*}{$h b$} & $5^{\prime}(-3557) R$ & $\mathrm{~T}$ & $\mathrm{~T}$ & $\mathrm{~T}$ & $\mathrm{~T}$ & G & A & $T$ & A & $\mathrm{G}$ & C & A & G & $T$ & $\mathrm{~T}$ & A & $\mathrm{C}$ & G & $T$ & $T$ & $\mathrm{~T}$ & C & G & & & \\
\hline & coincidence & $\circ$ & $\circ$ & $\circ$ & $\circ$ & $\circ$ & $\circ$ & $\circ$ & & $\circ$ & & & $\circ$ & & $\circ$ & & & $\circ$ & & & & & & & & \\
\hline & & & & & & & & & & & & & & & & & & & & & & & & & & \\
\hline$b c d$ & dme-miR-1000 & A & $\mathrm{T}$ & A & $\mathrm{T}$ & $\mathrm{T}$ & G & $\mathrm{T}$ & C & C & $\mathrm{T}$ & $G$ & $\mathrm{~T}$ & C & $A$ & C & A & $G$ & C & A & $\mathrm{G}$ & $\mathrm{T}$ & & & & \\
\hline \multirow[t]{2}{*}{$h b$} & $5^{\prime}(-4657) \mathrm{F}$ & $\mathrm{G}$ & $\mathrm{T}$ & A & $T$ & $T$ & G & $T$ & A & $T$ & A & $G$ & A & $G$ & $A$ & A & A & A & A & A & $\mathrm{G}$ & G & & & & \\
\hline & coincidence & & $\circ$ & $\circ$ & $\circ$ & $\circ$ & $\circ$ & $\circ$ & & & & $\circ$ & & & $\circ$ & & $\circ$ & & & $\circ$ & $\circ$ & & & & & \\
\hline \multirow{2}{*}{$h b$} & $5^{\prime}(-1192) F$ & $G$ & $T$ & A & $\mathrm{T}$ & $\mathrm{T}$ & G & $T$ & A & $G$ & A & $\mathrm{T}$ & A & $\mathrm{T}$ & $\mathrm{T}$ & $T$ & $\mathrm{~T}$ & A & $G$ & C & $\mathrm{T}$ & G & & & & \\
\hline & coincidence & & $\circ$ & $\circ$ & $\circ$ & $\circ$ & $\circ$ & $\circ$ & & & & & & & & & & & & & & & & & & \\
\hline & & & & & & & & & & & & & & & & & & & & & & & & & & \\
\hline$h b$ & $5^{\prime}(-296) \mathrm{F}$ & A & $T$ & A & $T$ & $T$ & G & $T$ & $\mathrm{~T}$ & A & $G$ & $\mathrm{C}$ & C & A & $T$ & $T$ & A & $C$ & C & A & A & G & & & & \\
\hline & coincidence & $\circ$ & $\circ$ & $\circ$ & $\circ$ & $\circ$ & $\circ$ & $\circ$ & & & & & & & & & $\circ$ & & $\circ$ & $\circ$ & & & & & & \\
\hline$h b$ & $5^{\prime}(-2533) R$ & A & $\mathrm{T}$ & A & $\mathrm{T}$ & $\mathrm{T}$ & G & $\mathrm{T}$ & $\mathrm{T}$ & $\mathrm{T}$ & $\mathrm{T}$ & A & G & $A$ & A & $\mathrm{T}$ & $\mathrm{T}$ & $\mathrm{T}$ & $\mathrm{T}$ & $\mathrm{T}$ & $\mathrm{G}$ & C & & & & \\
\hline & coincidence & $\circ$ & ० & $\circ$ & $\circ$ & $\circ$ & $\circ$ & $\circ$ & & & $\circ$ & & & & $\circ$ & & & & & & $\circ$ & & & & & \\
\hline
\end{tabular}

$5^{\prime}(-x x x x) F / R: x x x x$-start position in $5^{\prime}$ upstream, F-Forward strand, R-Reverse strand 
Citation: Takasaki S (2013) Roles of miRNAs in Early Embryonic Development of Drosophila melanogaster. Genetics 2: 122. doi:10.4172/21611041.1000122

\begin{tabular}{|c|c|c|c|c|c|c|c|c|c|c|c|c|c|c|c|c|c|c|c|c|c|c|c|c|}
\hline$b c d$ & dme-miR-283 & $\mathrm{T}$ & A & A & A & $\mathrm{T}$ & A & $\mathrm{T}$ & C & A & $G$ & C & $\mathrm{T}$ & $G$ & G & $\mathrm{T}$ & A & A & $\mathrm{T}$ & $\mathrm{T}$ & C & $T$ & & \\
\hline \multirow[t]{2}{*}{$h b$} & $5^{\prime}(-4897) \mathrm{F}$ & $\mathrm{T}$ & A & A & A & $\mathrm{T}$ & A & $\mathrm{T}$ & $T$ & G & C & $T$ & $T$ & $\mathrm{~T}$ & $\mathrm{~T}$ & A & C & A & $\mathrm{T}$ & $T$ & $\mathrm{~T}$ & T & & \\
\hline & coincidence & $\circ$ & $\circ$ & $\circ$ & $\circ$ & $\circ$ & $\circ$ & $\circ$ & & & & & $\circ$ & & & & & $\circ$ & $\circ$ & $\circ$ & & $\circ$ & & \\
\hline \multirow[t]{2}{*}{$h b$} & $5^{\prime}(-4820) F$ & A & $A$ & A & $A$ & $T$ & A & $T$ & $T$ & $\mathrm{C}$ & G & A & $\mathrm{C}$ & A & $T$ & A & $A$ & $A$ & $C$ & A & $G$ & G & & \\
\hline & coincidence & & o & $\circ$ & $\circ$ & $\circ$ & $\circ$ & $\circ$ & & & $\circ$ & & & & & & $\circ$ & $\circ$ & & & & & & \\
\hline \multirow[t]{2}{*}{$h b$} & $5^{\prime}(-4788) F$ & C & A & A & A & $\mathrm{T}$ & A & $\mathrm{T}$ & T & C & C & A & C & A & $\mathrm{T}$ & A & A & A & C & A & G & G & & \\
\hline & coincidence & & $\circ$ & $\circ$ & $\circ$ & $\circ$ & $\circ$ & $\circ$ & & & & & & & & & $\circ$ & $\circ$ & & & & & & \\
\hline \multirow[t]{2}{*}{$h b$} & $5^{\prime}(-3555) \mathrm{F}$ & $C$ & $A$ & A & $A$ & $T$ & A & $T$ & $T$ & G & $C$ & A & $T$ & $T$ & $A$ & A & A & $T$ & A & C & $A$ & A & & \\
\hline & coincidence & & $\circ$ & $\circ$ & $\circ$ & $\circ$ & $\circ$ & $\circ$ & & & & & $\circ$ & & & & $\circ$ & & & & & & & \\
\hline \multirow[t]{2}{*}{$h b$} & $5^{\prime}(-2134) F$ & $C$ & A & A & $A$ & $T$ & A & $T$ & A & A & $T$ & G & A & A & $T$ & A & $C$ & A & $C$ & C & $T$ & A & & \\
\hline & coincidence & & $\circ$ & $\circ$ & $\circ$ & $\circ$ & $\circ$ & $\circ$ & & $\circ$ & & & & & & & & $\circ$ & & & & & & \\
\hline \multirow[t]{2}{*}{$h b$} & $5^{\prime}(-1948) F$ & $\mathrm{~T}$ & A & A & A & $\mathrm{T}$ & A & $\mathrm{T}$ & G & C & A & C & A & $\mathrm{T}$ & A & $\mathrm{T}$ & A & $\mathrm{T}$ & A & C & G & G & & \\
\hline & coincidence & o & $\circ$ & o & o & $\circ$ & o & o & & & & o & & & & o & $\circ$ & & & & & & & \\
\hline \multirow[t]{2}{*}{$h b$} & $5^{\prime}(-1283) F$ & A & A & A & A & $\mathrm{T}$ & A & $\mathrm{T}$ & C & C & A & C & A & A & A & A & G & C & $\mathrm{G}$ & A & A & T & & \\
\hline & coincidence & & $\circ$ & $\circ$ & $\circ$ & $\circ$ & $\circ$ & $\circ$ & $\circ$ & & & $\circ$ & & & & & & & & & & $\circ$ & & \\
\hline \multirow[t]{2}{*}{$h b$} & $5^{\prime}(-1258) \mathrm{F}$ & $\mathrm{T}$ & A & A & A & $\mathrm{T}$ & A & $\mathrm{T}$ & G & C & $\mathrm{T}$ & A & A & G & C & $\mathrm{T}$ & $\mathrm{T}$ & $C$ & A & $T$ & $T$ & $\mathrm{~T}$ & & \\
\hline & coincidence & $\circ$ & $\circ$ & $\circ$ & $\circ$ & $\circ$ & $\circ$ & $\circ$ & & & & & & $\circ$ & & $\circ$ & & & & $\circ$ & & $\circ$ & & \\
\hline \multirow[t]{2}{*}{$h b$} & $5^{\prime}(-1019) F$ & A & A & A & A & $T$ & A & $\mathrm{T}$ & A & G & G & C & A & A & C & A & A & G & C & A & A & T & & \\
\hline & coincidence & & $\circ$ & o & $\circ$ & $\circ$ & $\circ$ & o & & & ○ & $\circ$ & & & & & $\circ$ & & & & & $\circ$ & & \\
\hline \multirow[t]{2}{*}{$h b$} & $5^{\prime}(-2531) R$ & $A$ & $A$ & A & $A$ & $T$ & A & $T$ & $T$ & $\mathrm{G}$ & $T$ & $T$ & $T$ & $T$ & $A$ & G & $A$ & A & $T$ & $T$ & $T$ & $T$ & & \\
\hline & coincidence & & $\circ$ & $\circ$ & $\circ$ & $\circ$ & $\circ$ & $\circ$ & & & & & $\circ$ & & & & $\circ$ & $\circ$ & $\circ$ & $\circ$ & & $\circ$ & & \\
\hline \multirow[t]{2}{*}{$h b$} & $5^{\prime}(-1917) R$ & $\mathrm{~T}$ & A & A & A & $\mathrm{T}$ & A & $\mathrm{T}$ & A & $\mathrm{T}$ & $C$ & C & C & $\mathrm{G}$ & $\mathrm{T}$ & A & $\mathrm{T}$ & A & A & $T$ & A & $\mathrm{T}$ & & \\
\hline & coincidence & $\circ$ & $\circ$ & $\circ$ & $\circ$ & $\circ$ & $\circ$ & $\circ$ & & & & $\circ$ & & $\circ$ & & & & $\circ$ & & $\circ$ & & ○ & & \\
\hline$h b$ & $5^{\prime}(-1767) R$ & A & A & A & A & $\mathrm{T}$ & A & $\mathrm{T}$ & A & $\mathrm{T}$ & G & $\mathrm{T}$ & A & $\mathrm{T}$ & G & $\mathrm{T}$ & A & $\mathrm{T}$ & G & C & G & T & & \\
\hline & coincidence & & o & o & o & $\circ$ & o & o & & & o & & & & o & o & $\circ$ & & & & & o & & \\
\hline$h b$ & $5^{\prime}(-1630) R$ & A & A & A & A & $T$ & A & $\mathrm{T}$ & C & A & $\mathrm{T}$ & G & A & A & A & A & $\mathrm{T}$ & G & $\mathrm{G}$ & C & A & A & & \\
\hline & coincidence & & $\circ$ & $\circ$ & $\circ$ & $\circ$ & $\circ$ & $\circ$ & $\circ$ & $\circ$ & & & & & & & & & & & & & & \\
\hline$h b$ & $5^{\prime}(-1179) R$ & A & A & A & A & $\mathrm{T}$ & A & $\mathrm{T}$ & C & $\mathrm{T}$ & A & C & A & A & $\mathrm{T}$ & A & C & $\mathrm{T}$ & $\mathrm{T}$ & A & G & G & & \\
\hline & coincidence & & $\circ$ & $\circ$ & $\circ$ & $\circ$ & $\circ$ & o & o & & & $\circ$ & & & & & & & $\circ$ & & & & & \\
\hline$h b$ & $5^{\prime}(-1092) R$ & $\mathrm{~T}$ & A & A & A & $\mathrm{T}$ & A & $\mathrm{T}$ & T & A & $\mathrm{T}$ & $\mathrm{T}$ & A & A & $\mathrm{T}$ & $\mathrm{T}$ & T & C & G & C & A & A & & \\
\hline & coincidence & o & o & o & o & $\circ$ & o & $\circ$ & & $\circ$ & & & & & & o & & & & & & & & \\
\hline$b c d$ & dme-miR-989 & $\mathrm{T}$ & G & $\mathrm{T}$ & G & A & $\mathrm{T}$ & G & $\mathrm{T}$ & G & A & C & G & $\mathrm{T}$ & A & G & T & G & G & A & A & C & & \\
\hline$h b$ & $5^{\prime}(-2869) \mathrm{F}$ & $\mathrm{T}$ & G & $T$ & G & A & $T$ & A & $T$ & A & C & $\mathrm{T}$ & $\mathrm{T}$ & $\mathrm{T}$ & C & A & A & A & A & G & A & A & & \\
\hline & coincidence & o & $\circ$ & o & $\circ$ & $\circ$ & $\circ$ & & o & & & & & $\circ$ & & & & & & & $\circ$ & & & \\
\hline$b c d$ & dme-miR-1017 & G & A & A & A & G & C & $\mathrm{T}$ & C & $\mathrm{T}$ & A & C & C & C & A & A & A & C & $\mathrm{T}$ & C & A & T & C & C \\
\hline$h b$ & $5^{\prime}(-4333) \mathrm{F}$ & $\mathrm{C}$ & A & A & A & G & C & $T$ & $T$ & $\mathrm{~T}$ & G & C & $\mathrm{C}$ & $C$ & A & A & A & $T$ & $T$ & A & A & G & $T$ & $T$ \\
\hline & coincidence & & o & o & $\circ$ & $\circ$ & $\circ$ & o & & o & & $\circ$ & $\circ$ & $\circ$ & $\circ$ & o & $\circ$ & & $\circ$ & & $\circ$ & & & \\
\hline$h b$ & $5^{\prime}(-3078) \mathrm{F}$ & A & $A$ & A & $A$ & $G$ & C & $T$ & $T$ & $T$ & $C$ & C & G & $C$ & G & G & A & $T$ & A & A & $A$ & C & A & A \\
\hline & coincidence & & $\circ$ & $\circ$ & $\circ$ & $\circ$ & $\circ$ & $\circ$ & & $\circ$ & & $\circ$ & & $\circ$ & & & $\circ$ & & & & $\circ$ & & & \\
\hline$h b$ & $5^{\prime}(-4326) R$ & C & A & A & A & G & C & $\mathrm{T}$ & $T$ & $\mathrm{~T}$ & G & C & C & A & C & A & A & $\mathrm{T}$ & $\mathrm{T}$ & A & G & C & A & $T$ \\
\hline & coincidence & & $\circ$ & $\circ$ & $\circ$ & $\circ$ & $\circ$ & $\circ$ & & $\circ$ & & $\circ$ & $\circ$ & & & $\circ$ & $\circ$ & & $\circ$ & & & & & \\
\hline$h b$ & $5^{\prime}(-3070) R$ & G & A & A & A & G & C & $\mathrm{T}$ & T & $\mathrm{T}$ & $\mathrm{T}$ & G & C & G & C & A & A & $\mathrm{T}$ & $\mathrm{T}$ & T & C & T & A & C \\
\hline & coincidence & o & $\circ$ & o & $\circ$ & $\circ$ & o & o & & o & & & $\circ$ & & & $\circ$ & $\circ$ & & $\circ$ & & & $\circ$ & & o \\
\hline$b c d$ & dme-miR-79 & $\mathrm{T}$ & A & A & A & G & C & $\mathrm{T}$ & A & G & A & $\mathrm{T}$ & $\mathrm{T}$ & A & C & C & A & A & A & G & C & A & $\mathrm{T}$ & \\
\hline$h b$ & $5^{\prime}(-4333) F$ & $\mathrm{C}$ & A & A & $A$ & $G$ & C & $T$ & $T$ & $\mathrm{~T}$ & $\mathrm{G}$ & C & $\mathrm{C}$ & $C$ & A & A & A & $T$ & $T$ & A & $A$ & G & $T$ & \\
\hline & coincidence & & o & $\circ$ & o & $\circ$ & $\circ$ & o & & & & & & & & & $\circ$ & & & & & & $\circ$ & \\
\hline$h b$ & $5^{\prime}(-3078) F$ & $A$ & $A$ & A & $A$ & G & C & $\mathrm{T}$ & $T$ & $\mathrm{~T}$ & $C$ & C & G & $C$ & G & G & A & $T$ & A & A & $A$ & C & A & \\
\hline & coincidence & & $\circ$ & $\circ$ & $\circ$ & $\circ$ & $\circ$ & $\circ$ & & & & & & & & & $\circ$ & & $\circ$ & & & & & \\
\hline$h b$ & $5^{\prime}(-4326) R$ & C & A & A & A & G & C & $\mathrm{T}$ & $T$ & $\mathrm{~T}$ & $\mathrm{G}$ & C & C & A & C & A & A & $\mathrm{T}$ & $\mathrm{T}$ & A & G & C & A & \\
\hline & coincidence & & $\circ$ & $\circ$ & $\circ$ & $\circ$ & $\circ$ & $\circ$ & & & & & & $\circ$ & $\circ$ & & $\circ$ & & & & & & & \\
\hline$h b$ & $5^{\prime}(-3070) R$ & G & A & A & A & G & C & $\mathrm{T}$ & T & $\mathrm{T}$ & $\mathrm{T}$ & G & C & G & C & A & A & $\mathrm{T}$ & $\mathrm{T}$ & T & C & T & A & \\
\hline & coincidence & & $\circ$ & $\circ$ & $\circ$ & $\circ$ & $\circ$ & $\circ$ & & & & & & & $\circ$ & & $\circ$ & & & & $\circ$ & o & & \\
\hline
\end{tabular}

Table 2a: Relations between the miRNAs of $b c d$ and the 5 ' upstream region of $h$

The relations between the miRNAs of the $h b$ gene and the $5^{\prime}$ upstream region of the $b c d$ gene are listed in Table $2 \mathrm{~b}$, where it is clear that there also are many sequences common to these miRNAs and the 5 ' upstream region $h b$. They are, for example, "TGTGAT" (miR-989: -3194 to -3189 and -2445 to -2450 ), "ACAAGG” (miR-963: -3005 to
-3000 and -2191 to -2196$)$, “TTTAGAA" (miR-miR-927: -487 to -481 and -1646 to -1652 ) and "AATACTGT" (miR-8: -3597 to -3604$)$.

The relations between the cis-regulatory elements of Bcd and the miRNAs of the $b c d$ and $h b$ genes are shown in Figure 2. The expression 
Citation: Takasaki S (2013) Roles of miRNAs in Early Embryonic Development of Drosophila melanogaster. Genetics 2: 122. doi:10.4172/21611041.1000122

\begin{tabular}{|c|c|c|c|c|c|c|c|c|c|c|c|c|c|c|c|c|c|c|c|c|c|c|c|c|c|c|}
\hline gene & miRNA/5'region & 1 & 2 & 3 & 4 & 5 & 6 & 7 & 8 & 9 & 10 & 11 & 12 & 13 & 14 & 15 & 16 & 17 & 18 & 19 & 20 & 21 & 22 & 23 & & \multirow[t]{2}{*}{$4 \quad 2$} \\
\hline$h b$ & dme-miR-989 & $\mathrm{T}$ & $\mathrm{G}$ & $\mathrm{T}$ & G & A & $\mathrm{T}$ & G & $\mathrm{T}$ & G & A & C & G & $\mathrm{T}$ & A & $\mathrm{G}$ & $\mathrm{T}$ & G & G & A & A & C & & & & \\
\hline \multirow[t]{2}{*}{$b c d$} & $5^{\prime}(-3194) F$ & $\mathrm{~T}$ & G & $\mathrm{T}$ & G & A & $\mathrm{T}$ & $\mathrm{T}$ & $\mathrm{T}$ & A & $\mathrm{T}$ & G & G & C & A & $\mathrm{T}$ & G & G & C & G & C & A & & & & \\
\hline & coincidence & $\circ$ & $\circ$ & $\circ$ & $\circ$ & o & o & & $\circ$ & & & & $\circ$ & & $\circ$ & & & $\circ$ & & & & & & & & \\
\hline \multirow[t]{2}{*}{$b c d$} & $5^{\prime}(-3632) R$ & $G$ & $G$ & $T$ & G & A & $T$ & A & A & $G$ & A & $\mathrm{T}$ & $\mathrm{C}$ & $\mathrm{C}$ & $T$ & A & A & A & A & C & $\mathrm{G}$ & $T$ & & & & \\
\hline & coincidence & & $\circ$ & $\circ$ & $\circ$ & $\circ$ & $\circ$ & & & $\circ$ & $\circ$ & & & & & & & & & & & & & & & \\
\hline \multirow[t]{2}{*}{$b c d$} & $5^{\prime}(-2445) R$ & $T$ & $G$ & $T$ & $G$ & $A$ & $\mathrm{~T}$ & $T$ & $\mathrm{~T}$ & A & $A$ & $A$ & $\mathrm{~T}$ & $\mathrm{~T}$ & $T$ & $T$ & $\mathrm{C}$ & $\mathrm{C}$ & $A$ & $G$ & $A$ & A & & & & \\
\hline & coincidence & $\circ$ & $\circ$ & $\circ$ & $\circ$ & $\circ$ & $\circ$ & & $\circ$ & & $\circ$ & & & $\circ$ & & & & & & & $\circ$ & & & & & \\
\hline$h b$ & dme-miR-963 & A & C & A & A & G & G & $\mathrm{T}$ & A & A & A & $\mathrm{T}$ & A & $\mathrm{T}$ & C & A & G & G & $\mathrm{T}$ & $\mathrm{T}$ & G & $\mathrm{T}$ & $\mathrm{T}$ & T & & \\
\hline \multirow[t]{2}{*}{$b c d$} & $5^{\prime}(-3005) \mathrm{F}$ & A & $\mathrm{C}$ & A & A & G & G & $C$ & A & $\mathrm{T}$ & $\mathrm{T}$ & G & $G$ & $G$ & A & $T$ & $G$ & $G$ & $A$ & A & $\mathrm{C}$ & $\mathrm{T}$ & $T$ & G & & \\
\hline & coincidence & $\circ$ & $\circ$ & $\circ$ & $\circ$ & $\circ$ & $\circ$ & & $\circ$ & & & & & & & & $\circ$ & $\circ$ & & & & $\circ$ & $\circ$ & & & \\
\hline \multirow[t]{2}{*}{$b c d$} & $5^{\prime}(-2191) R$ & A & C & A & A & G & G & A & G & A & G & C & C & G & $\mathrm{T}$ & C & A & G & $\mathrm{T}$ & G & A & $\mathrm{T}$ & $\mathrm{T}$ & $\mathrm{T}$ & & \\
\hline & coincidence & $\circ$ & $\circ$ & $\circ$ & $\circ$ & $\circ$ & $\circ$ & & & $\circ$ & & & & & & & & $\circ$ & $\circ$ & & & $\circ$ & $\circ$ & $\circ$ & & \\
\hline \multirow[t]{2}{*}{$b c d$} & $5^{\prime}(-1471) R$ & C & C & A & A & G & G & A & $\mathrm{T}$ & A & C & A & C & A & C & A & A & A & G & G & $\mathrm{T}$ & A & C & A & & \\
\hline & coincidence & & $\circ$ & $\circ$ & $\circ$ & $\circ$ & $\circ$ & & & $\circ$ & & & & & $\circ$ & $\circ$ & & & & & & & & & & \\
\hline \multirow[t]{2}{*}{$b c d$} & $5^{\prime}(-1261) R$ & $\mathrm{G}$ & C & A & A & G & $G$ & C & C & $\mathrm{T}$ & $\mathrm{T}$ & A & A & $G$ & $\mathrm{~T}$ & $\mathrm{G}$ & A & A & A & $\mathrm{T}$ & A & $T$ & $T$ & $\mathrm{~T}$ & & \\
\hline & coincidence & & $\circ$ & $\circ$ & $\circ$ & $\circ$ & $\circ$ & & & & & & $\circ$ & & & & & & & $\circ$ & & $\circ$ & o & $\circ$ & & \\
\hline$h b$ & dme-miR-927 & $\mathrm{T}$ & $\mathrm{T}$ & $\mathrm{T}$ & A & G & A & A & $\mathrm{T}$ & $\mathrm{T}$ & C & C & $\mathrm{T}$ & A & C & G & C & $\mathrm{T}$ & $\mathrm{T}$ & $\mathrm{T}$ & A & C & C & & & \\
\hline \multirow[t]{2}{*}{$b c d$} & $5^{\prime}(-487) \mathrm{F}$ & $\mathrm{T}$ & $\mathrm{T}$ & $\mathrm{T}$ & A & G & A & A & C & A & $\mathrm{T}$ & $\mathrm{T}$ & C & A & C & C & $\mathrm{T}$ & $\mathrm{T}$ & $\mathrm{T}$ & $\mathrm{T}$ & $\mathrm{G}$ & $T$ & C & & & \\
\hline & coincidence & $\circ$ & $\circ$ & $\circ$ & $\circ$ & $\circ$ & $\circ$ & $\circ$ & & & & & & $\circ$ & $\circ$ & & & $\circ$ & $\circ$ & $\circ$ & & & $\circ$ & & & \\
\hline \multirow[t]{2}{*}{$b c d$} & $5^{\prime}(-1646) R$ & $\mathrm{~T}$ & $\mathrm{~T}$ & $\mathrm{~T}$ & A & G & A & A & A & $\mathrm{T}$ & $\mathrm{T}$ & $\mathrm{T}$ & A & $\mathrm{T}$ & $\mathrm{T}$ & C & A & A & A & A & A & C & A & & & \\
\hline & coincidence & $\circ$ & $\circ$ & $\circ$ & $\circ$ & $\circ$ & $\circ$ & $\circ$ & & $\circ$ & & & & & & & & & & & $\circ$ & $\circ$ & & & & \\
\hline \multirow[t]{2}{*}{$b c d$} & $5^{\prime}(-989) R$ & A & $\mathrm{T}$ & $\mathrm{T}$ & A & G & A & A & G & A & A & $\mathrm{T}$ & A & A & A & A & $\mathrm{G}$ & $\mathrm{G}$ & $\mathrm{T}$ & A & A & C & C & & & \\
\hline & coincidence & & $\circ$ & $\circ$ & $\circ$ & $\circ$ & $\circ$ & $\circ$ & & & & & & $\circ$ & & & & & $\circ$ & & $\circ$ & $\circ$ & $\circ$ & & & \\
\hline$h b$ & dme-miR-8 & $T$ & A & A & $T$ & A & $C$ & $\mathrm{~T}$ & $G$ & $T$ & $C$ & A & $G$ & $G$ & $\mathrm{~T}$ & A & A & A & $G$ & $A$ & $T$ & G & $T$ & C & & \\
\hline \multirow[t]{2}{*}{$b c d$} & $5^{\prime}(-3597) R$ & A & A & A & $\mathrm{T}$ & A & C & $\mathrm{T}$ & G & $\mathrm{T}$ & G & A & A & G & $\mathrm{G}$ & C & $\mathrm{G}$ & A & C & A & A & $\mathrm{T}$ & G & $T$ & & \\
\hline & coincidence & & $\circ$ & $\circ$ & $\circ$ & $\circ$ & $\circ$ & $\circ$ & $\circ$ & $\circ$ & & $\circ$ & & $\circ$ & & & & $\circ$ & & $\circ$ & & & & & & \\
\hline \multirow[t]{2}{*}{$b c d$} & $5^{\prime}(-2925) R$ & $G$ & A & A & $T$ & A & $\mathrm{C}$ & $T$ & G & $C$ & $\mathrm{~T}$ & $C$ & $T$ & $\mathrm{~T}$ & $T$ & A & A & A & $T$ & $A$ & $T$ & C & $C$ & $T$ & & \\
\hline & coincidence & & $\circ$ & $\circ$ & $\circ$ & $\circ$ & $\circ$ & $\circ$ & $\circ$ & & & & & & $\circ$ & $\circ$ & $\circ$ & $\circ$ & & $\circ$ & $\circ$ & & & & & \\
\hline$h b$ & dme-miR-315 & $\mathrm{T}$ & $\mathrm{T}$ & $\mathrm{T}$ & $T$ & G & A & $\mathrm{T}$ & $\mathrm{T}$ & G & $\mathrm{T}$ & $\mathrm{T}$ & G & $\mathrm{C}$ & $\mathrm{T}$ & $C$ & A & G & A & A & A & G & C & & & \\
\hline \multirow[t]{2}{*}{$b c d$} & $5^{\prime}(-2698) F$ & $G$ & $T$ & $T$ & $T$ & $G$ & $A$ & $T$ & G & $T$ & $G$ & $C$ & A & A & $A$ & $A$ & $T$ & $T$ & $T$ & $C$ & $A$ & C & $\mathrm{T}$ & & & \\
\hline & coincidence & & $\circ$ & $\circ$ & $\circ$ & $\circ$ & $\circ$ & $\circ$ & & & & & & & & & & & & & $\circ$ & & & & & \\
\hline$h b$ & dme-miR-976 & $\mathrm{T}$ & $\mathrm{T}$ & G & G & A & $\mathrm{T}$ & $\mathrm{T}$ & A & G & $\mathrm{T}$ & $\mathrm{T}$ & A & $\mathrm{T}$ & C & A & $\mathrm{T}$ & C & A & A & $\mathrm{T}$ & G & C & & & \\
\hline \multirow[t]{2}{*}{$b c d$} & $5^{\prime}(-3645) F$ & $T$ & $\mathrm{~T}$ & $G$ & $G$ & $A$ & $T$ & $C$ & $\mathrm{~T}$ & $T$ & $A$ & $T$ & $C$ & A & $C$ & $C$ & $C$ & $C$ & $T$ & $C$ & $G$ & G & $\mathrm{T}$ & & & \\
\hline & coincidence & $\circ$ & $\circ$ & $\circ$ & $\circ$ & $\circ$ & $\circ$ & & & & & $\circ$ & & & $\circ$ & & & $\circ$ & & & & $\circ$ & & & & \\
\hline \multirow[t]{2}{*}{$b c d$} & $5^{\prime}(-2760) F$ & C & $\mathrm{T}$ & G & G & A & $\mathrm{T}$ & C & $\mathrm{T}$ & C & G & A & $\mathrm{T}$ & C & A & A & $\mathrm{T}$ & $\mathrm{T}$ & A & G & $\mathrm{T}$ & $\mathrm{T}$ & C & & & \\
\hline & coincidence & & $\circ$ & $\circ$ & $\circ$ & $\circ$ & $\circ$ & & & & & & & & & $\circ$ & $\circ$ & & $\circ$ & & $\circ$ & & $\circ$ & & & \\
\hline$b c d$ & $5^{\prime}(-2140) F$ & $\mathrm{~T}$ & $\mathrm{~T}$ & G & G & A & $\mathrm{T}$ & G & C & A & G & G & $\mathrm{T}$ & $\mathrm{T}$ & C & A & G & G & $\mathrm{T}$ & C & C & $\mathrm{T}$ & G & & & \\
\hline & coincidence & 0 & $\circ$ & $\circ$ & $\circ$ & $\circ$ & $\circ$ & & & & & & & $\circ$ & $\circ$ & $\circ$ & & & & & & & & & & \\
\hline
\end{tabular}

Table 2(b). Relations between the miRNAs of $h b$ and the 5 ' upstream region of $b c d$.

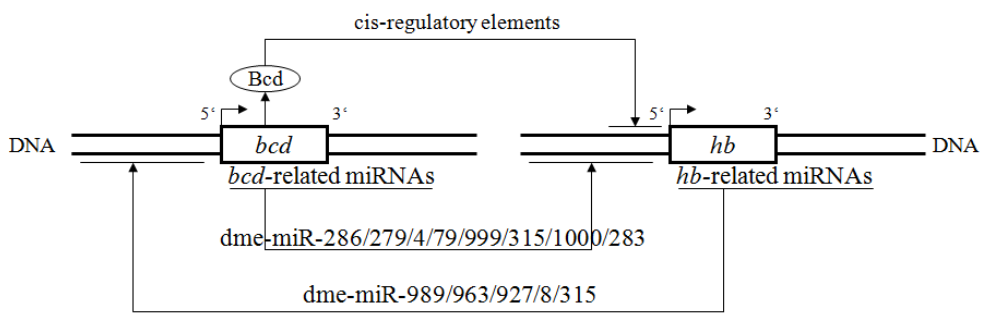

Figure 2: Relations between cis-regulatory elements and individual miRNAs for $b c d$ and $h b$ (bcd-related and $h b$-related miRNAs from Table 1).

of the gene $h b$ is well known to be regulated by Bcd cis-regulatory elements, and the consensus sequences of the miRNAs of the $b c d$ and $h b$ genes might also be related to the regulation of $h b$ expression.

Since there are many $b c d$ miRNAs with sequences occurring in $h b$ and there are many $h b$ miRNAs with sequences occurring in $b c d$, these miRNAs might play roles in the regulation of both genes. One hypothetical regulatory sequence is shown in Figure 3. To bind the
Bcd cis-regulatory elements to the 5' upstream regions of the gene $h b$, it might be necessary for one gene to inquire about the status of the other and for both to respond to these inquiries. The miRNAs of both genes might mediate these inquiries and responses. The following is a hypothetical regulatory sequence involving interaction between $b c d$ and $h b$ :

1. Some miRNA of bcd

(dme- 
Citation: Takasaki S (2013) Roles of miRNAs in Early Embryonic Development of Drosophila melanogaster. Genetics 2: 122. doi:10.4172/21611041.1000122

Page 6 of 14

miR-79/4/286/279/996/999/315/1000/283/989/1017) inquires whether $h b$ is ready to receive the protein $\mathrm{Bcd}$.

2. After receiving the $b c d$ inquiry of these miRNAs, $h b$ responds that it is ready to receive $\mathrm{Bcd}$. This response is carried by some miRNA of $h b$ (dme-miR-989/963/927/8/315/976).

3. Upon receiving the response of $h b, b c d$ starts supplying Bcd to the 5' upstream region of $h b$.

4. When $h b$ recognizes that $\mathrm{Bcd}$ is bound to its 5 ' upstream region, it uses some miRNA (dme-miR-989/963/927/8/315/976) to respond that Bcd binding has started.

5. After receiving the start response of $h b, b c d$ continues to supply Bcd to the 5' upstream region of $h b$.

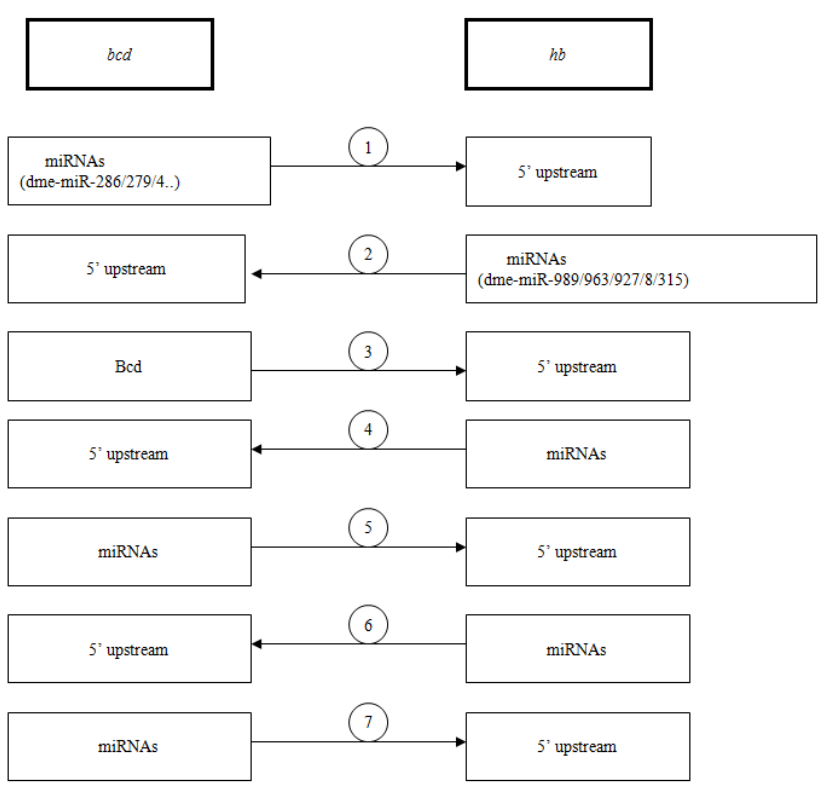

Figure 3: Regulatory sequences involved in the interaction between bcd and $h b$.

(a): bcd inquires whether it is possible to bind Bcd to the 5 ' upstream region of $h b$.

(b): $h b$ responds that the Bcd binding to its 5' upstream region is possible

(c): Bcd is supplied to the $5^{\prime}$ upstream region of $h b$.

(d): $h b$ responds that Bcd has started binding to the 5' upstream region.

(e): $b c d$ continues to supply Bcd to the 5' upstream region of $h b$.

(f): $h b$ responds that Bcd binding has been completed.

(g): bcd stops supplying Bcd to $h b$.
6. When $h b$ has bound a sufficient amount of Bcd, it uses dmemiR-989/963/927/8/315/976 to send the completed-binding signal to $b c d$.

7. After receiving the complete signal from $h b$, bcd stops supplying Bcd and uses dmemiR-79/4/286/279/996/999/315/1000/283/989/1017 to signal $h b$ that it has stopped the supply.

\section{Relations between cis-regulatory elements and individual miRNAs for eve, bcd, $h b, K r$, and $g t$}

Pair-rule genes of $D$. melanogaster are expressed in stripes, with a periodicity corresponding to alternate parasegments. Some pairrule genes (e.g. even-skipped) define odd-numbered parasegments, whereas others (e.g. fushitarazu) define even-numbered parasegments. Each pair-rule gene is expressed in seven stripes, each of which is only a few cells wide. One of the best-studied primary pair-rule genes is even-skipped (eve). As eve stripe 2 has been shown to be controlled by a 500-bp region that is activated by low concentrations of Bicoid and Hunchback proteins and is repressed by Giant and Krüppel proteins $[23,24]$, the relations between cis-regulatory elements and individual miRNAs of these genes were also examined. This stripe contains five binding sites for Bicoid, one site for Hunchback, three sites for Krüppel, and three sites for Giant. Cis-regulatory sequences for these genes (Table 3) were obtained from the Drosophila DNase I footprint database (Materials and Methods). The activators and repressors of the eve stripe 2 are shown in Figure 4. The miRNAs of these genes (Table 1) were obtained from miRBase [29,30]. Relations between individual miRNAs and 5' upstream regions of these genes were also obtained by using RSAT [31]. Sequence coincidences between individual miRNAs and 5' upstream regions for these genes are listed in Tables $4 \mathrm{a}$ and $4 \mathrm{~h}$.

The seven or eight nucleotide length consensus sequences for dme-miR-4, dme-miR-286/279/996, dme-miR-315, dme-miR-1000, and dme-miR-283 of $b c d$ and the 5' upstream region of eve are respectively "ATAAAGC", "TGACTAGA" "TTTGATT" "TATTGTCC" and "AAATATCA" (Table 4a). Similarly, the sequences common to dme-miR-315 of eve and the 5' upstream region of $b c d$ is "TTTTGA" (Table 4(b)). These miRNAs might mediate inquiries and responses in the regulation of $b c d$ and $h b$. In both $h b$ and eve genes, dmemiR-989/963/8/315/976 and dme-miR-315 might play regulatory roles by binding the common sequences listed in Tables $4 \mathrm{c}$ and $4 \mathrm{~d}$. Similarly, dme-miR-277/274/305/315/263b/316/1011/283 and dme-miR-315 might play roles in the regulation of $K r$ and eve by binding the common sequences listed in Tables $4 \mathrm{e}$ and 4f, and dme-miR-999/1014/1006/10$3 \mathrm{p}$ and dme-miR-315 might play roles in the regulation of $g t$ and eve

\begin{tabular}{|c|c|c|c|c|}
\hline Gene & Function & Start & end & sequences \\
\hline$b c d-1$ & A & -1091 & -1081 & GAAGGGATTAG \\
\hline$b c d-2$ & A & -1199 & -1191 & G G GATTAG C \\
\hline$b c d-3$ & A & -1292 & -1284 & TATAATCGC \\
\hline$b c d-4$ & A & -1442 & -1434 & G A G TA T TAT T \\
\hline$b c d-5$ & A & -1463 & -1455 & G T TAATCCG \\
\hline$h b-3$ & A & -1106 & -1097 & CATAAAAACA \\
\hline$K r-3$ & $\mathrm{R}$ & -1091 & -1081 & GAAG G G AT TAG \\
\hline$K r-4$ & $\mathrm{R}$ & -1275 & -1266 & A C C G G G T T G C \\
\hline$K r-5$ & $\mathrm{R}$ & -1462 & -1453 & T TAATCCGTT \\
\hline$g t-1$ & $\mathrm{R}$ & -1112 & -1090 & GAAAGTCATAAAAACACATAATA \\
\hline \multirow[t]{2}{*}{$g t-2$} & $\mathrm{R}$ & -1380 & -1336 & GACTTTATTGCATCTTGAACA \\
\hline & & & & ATCGTCGCAGTTTGGTAACAC \\
\hline$g t-3$ & $\mathrm{R}$ & -1443 & -1418 & C GAGATTATTAGTCAATTG CAGTTG C \\
\hline
\end{tabular}

A: activator, $\mathrm{R}$ : repressor

Table 3: Repressors and activators of eve stripe 2 
Citation: Takasaki S (2013) Roles of miRNAs in Early Embryonic Development of Drosophila melanogaster. Genetics 2: 122. doi:10.4172/21611041.1000122

\begin{tabular}{|c|c|c|c|c|c|c|c|c|c|c|c|c|c|c|c|c|c|c|c|c|c|c|c|c|c|c|}
\hline gene & miRNA/5'region & 1 & 2 & 3 & 4 & 5 & 6 & 7 & 8 & 9 & 10 & 11 & 12 & 13 & 14 & 15 & 16 & 17 & 18 & 19 & 20 & 21 & 22 & 23 & 24 & 25 \\
\hline$b c d$ & dme-miR-79 & $\mathrm{T}$ & A & $A$ & A & G & C & $T$ & A & $G$ & A & $\mathrm{T}$ & $\mathrm{T}$ & $A$ & C & C & A & $A$ & $A$ & $G$ & $\mathrm{C}$ & $A$ & $\mathrm{~T}$ & & & \\
\hline \multirow[t]{2}{*}{ eve } & $5^{\prime}(-1599) F$ & A & A & $A$ & $A$ & G & C & $T$ & G & G & $\mathrm{C}$ & $\mathrm{C}$ & $\mathrm{T}$ & $\mathrm{G}$ & G & $\mathrm{T}$ & $\mathrm{T}$ & $\mathrm{T}$ & $\mathrm{C}$ & $T$ & $\mathrm{C}$ & G & $\mathrm{C}$ & & & \\
\hline & coincidence & & $\circ$ & $\circ$ & $\circ$ & $\circ$ & $\circ$ & $\circ$ & & $\circ$ & & & $\circ$ & & & & & & & & $\circ$ & & & & & \\
\hline$b c d$ & dme-miR-4 & A & $\mathrm{T}$ & $A$ & $A$ & A & G & $\mathrm{C}$ & $\mathrm{T}$ & A & G & A & $\mathrm{C}$ & $A$ & A & $\mathrm{C}$ & C & $A$ & $\mathrm{~T}$ & $T$ & $G$ & A & & & & \\
\hline \multirow[t]{2}{*}{ eve } & $5^{\prime}(-2225) F$ & A & $\mathrm{T}$ & A & A & A & G & $\mathrm{C}$ & G & G & C & A & $A$ & $C$ & A & A & $\mathrm{T}$ & $\mathrm{C}$ & G & G & $C$ & A & & & & \\
\hline & coincidence & $\circ$ & $\circ$ & $\circ$ & $\circ$ & $\circ$ & $\circ$ & $\circ$ & & & & $\circ$ & & & $\circ$ & & & & & & & $\circ$ & & & & \\
\hline$b c d$ & dme-miR-286 & $\mathrm{T}$ & $G$ & $A$ & $\mathrm{C}$ & $\mathrm{T}$ & A & $G$ & A & $\mathrm{C}$ & $\mathrm{C}$ & G & $A$ & $A$ & $\mathrm{C}$ & $A$ & $\mathrm{C}$ & $\mathrm{T}$ & $C$ & G & $\mathrm{T}$ & G & $\mathrm{C}$ & $\mathrm{T}$ & & \\
\hline \multirow[t]{2}{*}{ eve } & $5^{\prime}(-4015) F$ & G & $G$ & $A$ & $\mathrm{C}$ & $\mathrm{T}$ & A & G & G & A & A & C & $\mathrm{T}$ & $G$ & C & $A$ & A & $A$ & $C$ & $\mathrm{~T}$ & $A$ & G & $\mathrm{C}$ & $A$ & & \\
\hline & coincidence & & $\circ$ & $\circ$ & $\circ$ & $\circ$ & $\circ$ & $\circ$ & & & & & & & $\circ$ & $\circ$ & & & $\circ$ & & & $\circ$ & $\circ$ & & & \\
\hline \multirow[t]{2}{*}{ eve } & $5^{\prime}(-2900) \mathrm{F}$ & $\mathrm{T}$ & G & A & $\mathrm{C}$ & $\mathrm{T}$ & $A$ & $\mathrm{G}$ & A & A & A & $\mathrm{T}$ & $A$ & $\mathrm{~T}$ & $\mathrm{C}$ & $A$ & $A$ & A & $\mathrm{G}$ & $T$ & $\mathrm{C}$ & $T$ & $\mathrm{~T}$ & $T$ & & \\
\hline & coincidence & $\circ$ & $\circ$ & $\circ$ & $\circ$ & $\circ$ & $\circ$ & $\circ$ & $\circ$ & & & & $\circ$ & & $\circ$ & $\circ$ & & & & & & & & & & \\
\hline \multirow[t]{2}{*}{ eve } & $5^{\prime}(-1141) \mathrm{F}$ & G & G & A & $\mathrm{C}$ & $\mathrm{T}$ & A & G & C & G & A & A & $\mathrm{C}$ & $\mathrm{T}$ & G & $\mathrm{G}$ & G & $\mathrm{T}$ & $\mathrm{T}$ & A & $\mathrm{T}$ & $\mathrm{T}$ & $\mathrm{T}$ & $\mathrm{T}$ & & \\
\hline & coincidence & & $\circ$ & $\circ$ & $\circ$ & $\circ$ & $\circ$ & $\circ$ & & & & & & & & & & $\circ$ & & & $\circ$ & & & $\circ$ & & \\
\hline$b c d$ & dme-miR-279 & $\mathrm{T}$ & G & A & $\mathrm{C}$ & $\mathrm{T}$ & A & G & A & $\mathrm{T}$ & C & C & A & $C$ & A & C & $\mathrm{T}$ & $\mathrm{C}$ & A & $\mathrm{T}$ & $\mathrm{T}$ & A & A & & & \\
\hline eve & $5^{\prime}(-4015) F$ & G & G & A & $\mathrm{C}$ & $\mathrm{T}$ & A & G & G & A & A & C & $\mathrm{T}$ & G & C & A & A & A & $C$ & $\mathrm{~T}$ & A & G & $\mathrm{C}$ & & & \\
\hline & coincidence & & $\circ$ & $\circ$ & $\circ$ & $\circ$ & $\circ$ & $\circ$ & & & & $\circ$ & & & & & & & & $\circ$ & & & & & & \\
\hline eve & $5^{\prime}(-2900) \mathrm{F}$ & $\mathrm{T}$ & G & A & $\mathrm{C}$ & $\mathrm{T}$ & $A$ & G & A & A & A & $\mathrm{T}$ & $A$ & $\mathrm{~T}$ & $\mathrm{C}$ & $A$ & $A$ & $A$ & $G$ & $T$ & $C$ & $T$ & $\mathrm{~T}$ & & & \\
\hline & coincidence & $\circ$ & $\circ$ & $\circ$ & $\circ$ & $\circ$ & $\circ$ & $\circ$ & $\circ$ & & & & $\circ$ & & & & & & & $\circ$ & & & & & & \\
\hline eve & $5^{\prime}(-1141) \mathrm{F}$ & G & G & A & $\mathrm{C}$ & $\mathrm{T}$ & A & G & C & G & A & $A$ & $\mathrm{C}$ & $\mathrm{T}$ & G & G & $\mathrm{G}$ & $\mathrm{T}$ & $\mathrm{T}$ & A & $T$ & $T$ & $\mathrm{~T}$ & & & \\
\hline & coincidence & & $\circ$ & $\circ$ & $\circ$ & $\circ$ & $\circ$ & $\circ$ & & & & & & & & & & & & & $\circ$ & & & & & \\
\hline$b c d$ & dme-miR-996 & $\mathrm{T}$ & G & A & $\mathrm{C}$ & $T$ & $A$ & G & A & $T$ & $\mathrm{~T}$ & $T$ & $\mathrm{C}$ & $A$ & $T$ & $\mathrm{G}$ & $\mathrm{C}$ & $\mathrm{T}$ & $\mathrm{C}$ & $G$ & $\mathrm{~T}$ & $\mathrm{C}$ & $\mathrm{T}$ & & & \\
\hline eve & $5^{\prime}(-4015) F$ & G & G & A & $\mathrm{C}$ & $\mathrm{T}$ & $A$ & G & $G$ & $A$ & A & $\mathrm{C}$ & $\mathrm{T}$ & $G$ & $\mathrm{C}$ & $A$ & A & $A$ & $C$ & $T$ & $A$ & G & $\mathrm{C}$ & & & \\
\hline & coincidence & & $\circ$ & $\circ$ & $\circ$ & $\circ$ & $\circ$ & $\circ$ & & & & & & & & & & & $\circ$ & & & & & & & \\
\hline eve & $5^{\prime}(-2900) \mathrm{F}$ & $\mathrm{T}$ & G & A & $\mathrm{C}$ & $T$ & $A$ & G & A & A & A & $T$ & $A$ & $\mathrm{~T}$ & $\mathrm{C}$ & $A$ & $A$ & $A$ & $\mathrm{G}$ & $T$ & $\mathrm{C}$ & $T$ & $\mathrm{~T}$ & & & \\
\hline & coincidence & $\circ$ & $\circ$ & $\circ$ & $\circ$ & $\circ$ & $\circ$ & $\circ$ & $\circ$ & & & $\circ$ & & & & & & & & & & & $\circ$ & & & \\
\hline eve & $5^{\prime}(-1141) \mathrm{F}$ & G & G & $A$ & $\mathrm{C}$ & $\mathrm{T}$ & A & G & $\mathrm{C}$ & G & A & A & $\mathrm{C}$ & $\mathrm{T}$ & G & $\mathrm{G}$ & $\mathrm{G}$ & $\mathrm{T}$ & $\mathrm{T}$ & $A$ & $\mathrm{~T}$ & $T$ & $\mathrm{~T}$ & & & \\
\hline & coincidence & & $\circ$ & $\circ$ & $\circ$ & $\circ$ & $\circ$ & $\circ$ & & & & & $\circ$ & & & $\circ$ & & $\circ$ & & & $\circ$ & & $\circ$ & & & \\
\hline$b c d$ & dme-miR-999 & $\mathrm{T}$ & G & $\mathrm{T}$ & $T$ & A & $A$ & $\mathrm{C}$ & $\mathrm{T}$ & G & $\mathrm{T}$ & A & $A$ & $\mathrm{G}$ & $A$ & $\mathrm{C}$ & $\mathrm{T}$ & $\mathrm{G}$ & $T$ & G & $\mathrm{T}$ & G & $\mathrm{T}$ & $C$ & $\mathrm{~T}$ & \\
\hline eve & $5^{\prime}(-1567) F$ & $\mathrm{~T}$ & G & $\mathrm{T}$ & $\mathrm{T}$ & A & A & $T$ & $\mathrm{C}$ & $\mathrm{C}$ & G & $\mathrm{T}$ & $\mathrm{T}$ & $\mathrm{T}$ & G & $\mathrm{C}$ & $\mathrm{C}$ & $A$ & $\mathrm{~T}$ & C & $A$ & G & $\mathrm{C}$ & $G$ & A & \\
\hline & coincidence & $\circ$ & $\circ$ & $\circ$ & $\circ$ & $\circ$ & $\circ$ & & & & & & & & & $\circ$ & & & $\circ$ & & & $\circ$ & & & & \\
\hline eve & $5^{\prime}(-699) \mathrm{F}$ & $\mathrm{T}$ & G & $\mathrm{T}$ & $T$ & A & $A$ & $A$ & $\mathrm{C}$ & G & $\mathrm{T}$ & G & $\mathrm{C}$ & $\mathrm{G}$ & G & $\mathrm{C}$ & $A$ & $\mathrm{~T}$ & $A$ & $A$ & $\mathrm{~T}$ & $A$ & $\mathrm{~T}$ & $T$ & A & \\
\hline & coincidence & $\circ$ & $\circ$ & $\circ$ & $\circ$ & $\circ$ & $\circ$ & & & $\circ$ & $\circ$ & & & $\circ$ & & $\circ$ & & & & & $\circ$ & & $\circ$ & & & \\
\hline$b c d$ & dme-miR-315 & $\mathrm{T}$ & $\mathrm{T}$ & $\mathrm{T}$ & $\mathrm{T}$ & G & A & $T$ & $\mathrm{~T}$ & G & $\mathrm{T}$ & $\mathrm{T}$ & $\mathrm{G}$ & $C$ & $T$ & $\mathrm{C}$ & $A$ & $\mathrm{G}$ & $A$ & $A$ & $A$ & G & $\mathrm{C}$ & & & \\
\hline eve & $5^{\prime}(-4983) R$ & $\mathrm{~T}$ & $\mathrm{~T}$ & $\mathrm{~T}$ & $\mathrm{~T}$ & G & A & $\mathrm{T}$ & $\mathrm{T}$ & C & G & $\mathrm{T}$ & A & $C$ & G & A & $A$ & $\mathrm{G}$ & $\mathrm{T}$ & $\mathrm{T}$ & $\mathrm{T}$ & C & $\mathrm{T}$ & & & \\
\hline & coincidence & $\circ$ & $\circ$ & $\circ$ & $\circ$ & $\circ$ & $\circ$ & $\circ$ & $\circ$ & & & $\circ$ & & $\circ$ & & & $\circ$ & $\circ$ & & & & & & & & \\
\hline eve & $5^{\prime}(-4610) R$ & A & $\mathrm{T}$ & $\mathrm{T}$ & $\mathrm{T}$ & $G$ & A & $T$ & $\mathrm{~T}$ & A & $\mathrm{T}$ & $A$ & $\mathrm{~T}$ & $\mathrm{~T}$ & $A$ & $\mathrm{~T}$ & C & $\mathrm{G}$ & $\mathrm{T}$ & A & $\mathrm{T}$ & G & $\mathrm{C}$ & & & \\
\hline & coincidence & & $\circ$ & $\circ$ & $\circ$ & $\circ$ & $\circ$ & $\circ$ & $\circ$ & & $\circ$ & & & & & & & $\circ$ & & $\circ$ & & $\circ$ & o & & & \\
\hline eve & $5^{\prime}(-3001) R$ & A & $\mathrm{T}$ & $\mathrm{T}$ & $\mathrm{T}$ & G & A & $\mathrm{T}$ & G & A & G & G & A & G & $A$ & $\mathrm{~T}$ & $A$ & $\mathrm{~T}$ & $\mathrm{~T}$ & A & G & A & G & & & \\
\hline & coincidence & & $\circ$ & $\circ$ & $\circ$ & $\circ$ & $\circ$ & $\circ$ & & & & & & & & & $\circ$ & & & $\circ$ & & & & & & \\
\hline eve & $5^{\prime}(-2884) R$ & C & $\mathrm{T}$ & $\mathrm{T}$ & $\mathrm{T}$ & G & A & $\mathrm{T}$ & A & $T$ & $\mathrm{~T}$ & $\mathrm{~T}$ & $\mathrm{C}$ & $\mathrm{T}$ & A & $\mathrm{G}$ & $\mathrm{T}$ & $\mathrm{C}$ & A & A & $\mathrm{T}$ & $T$ & $\mathrm{C}$ & & & \\
\hline & coincidence & & $\circ$ & $\circ$ & $\circ$ & $\circ$ & $\circ$ & $\circ$ & & & $\circ$ & $\circ$ & & & & & & & $\circ$ & $\circ$ & & & 0 & & & \\
\hline$b c d$ & dme-miR-1000 & A & $\mathrm{T}$ & $A$ & $T$ & $T$ & G & $T$ & $\mathrm{C}$ & $\mathrm{C}$ & $\mathrm{T}$ & G & $\mathrm{T}$ & $C$ & $A$ & C & A & $\mathrm{G}$ & $C$ & $A$ & $\mathrm{G}$ & $T$ & & & & \\
\hline eve & $5^{\prime}(-4678) R$ & $\mathrm{~T}$ & $\mathrm{~T}$ & A & $T$ & $T$ & G & $T$ & A & $\mathrm{C}$ & A & $\mathrm{T}$ & $\mathrm{G}$ & $\mathrm{C}$ & $\mathrm{C}$ & $\mathrm{T}$ & C & $\mathrm{C}$ & $\mathrm{T}$ & $T$ & $\mathrm{~T}$ & A & & & & \\
\hline & coincidence & & $\circ$ & $\circ$ & $\circ$ & $\circ$ & $\circ$ & $\circ$ & & $\circ$ & & & & $\circ$ & & & & & & & & & & & & \\
\hline eve & $5^{\prime}(-1906) R$ & $\mathrm{C}$ & $\mathrm{T}$ & $A$ & $T$ & $\mathrm{~T}$ & G & $T$ & $\mathrm{C}$ & C & $A$ & $\mathrm{C}$ & $C$ & $\mathrm{~T}$ & C & C & G & $C$ & $\mathrm{C}$ & $G$ & $G$ & $\mathrm{C}$ & & & & \\
\hline & coincidence & & $\circ$ & $\circ$ & $\circ$ & $\circ$ & $\circ$ & $\circ$ & $\circ$ & $\circ$ & & & & & & $\circ$ & & & $\circ$ & & $\circ$ & & & & & \\
\hline$b c d$ & dme-miR-283 & $\mathrm{T}$ & A & $A$ & $A$ & $\mathrm{~T}$ & A & $T$ & $\mathrm{C}$ & $A$ & G & $\mathrm{C}$ & $\mathrm{T}$ & $G$ & G & $\mathrm{T}$ & $A$ & $A$ & $\mathrm{~T}$ & $T$ & $\mathrm{C}$ & $T$ & & & & \\
\hline eve & $5^{\prime}(-4650) F$ & $\mathrm{C}$ & A & A & $A$ & $\mathrm{~T}$ & A & $\mathrm{T}$ & G & A & $\mathrm{T}$ & A & $A$ & $A$ & $A$ & G & $\mathrm{T}$ & $A$ & $\mathrm{C}$ & $A$ & $A$ & $A$ & & & & \\
\hline & coincidence & & $\circ$ & $\circ$ & $\circ$ & $\circ$ & $\circ$ & $\circ$ & & $\circ$ & & & & & & & & $\circ$ & & & & & & & & \\
\hline eve & $5^{\prime}(-2893) \mathrm{F}$ & G & A & $A$ & $A$ & $T$ & $A$ & $T$ & $\mathrm{C}$ & A & A & A & $\mathrm{G}$ & $T$ & $\mathrm{C}$ & $\mathrm{T}$ & $\mathrm{T}$ & $\mathrm{T}$ & $T$ & $T$ & $G$ & $T$ & & & & \\
\hline & coincidence & & $\circ$ & $\circ$ & $\circ$ & $\circ$ & $\circ$ & $\circ$ & $\circ$ & $\circ$ & & & & & & $\circ$ & & & $\circ$ & $\circ$ & & $\circ$ & & & & \\
\hline eve & $5^{\prime}(-4558) R$ & $\mathrm{~T}$ & A & A & $A$ & $\mathrm{~T}$ & $A$ & $T$ & $\mathrm{~T}$ & A & $\mathrm{C}$ & A & $\mathrm{C}$ & $A$ & $A$ & $A$ & $\mathrm{~T}$ & $A$ & $C$ & $T$ & $A$ & $\mathrm{C}$ & & & & \\
\hline & coincidence & $\circ$ & $\circ$ & $\circ$ & $\circ$ & $\circ$ & $\circ$ & $\circ$ & & $\circ$ & & & & & & & & $\circ$ & & $\circ$ & & & & & & \\
\hline$b c d$ & dme-miR-989 & $\mathrm{T}$ & $G$ & $\mathrm{~T}$ & G & A & $\mathrm{T}$ & G & $\mathrm{T}$ & G & A & C & $\mathrm{G}$ & $\mathrm{T}$ & $A$ & $\mathrm{G}$ & $\mathrm{T}$ & $\mathrm{G}$ & $G$ & $A$ & $A$ & $\mathrm{C}$ & & & & \\
\hline eve & $5^{\prime}(-16) R$ & $\mathrm{~T}$ & G & $\mathrm{T}$ & G & A & $\mathrm{T}$ & $\mathrm{T}$ & $\mathrm{C}$ & A & A & A & $\mathrm{G}$ & $\mathrm{T}$ & $\mathrm{T}$ & $\mathrm{G}$ & G & $\mathrm{C}$ & $\mathrm{T}$ & $T$ & $A$ & $\mathrm{~T}$ & & & & \\
\hline & coincidence & $\circ$ & $\circ$ & $\circ$ & $\circ$ & $\circ$ & $\circ$ & & & & $\circ$ & & $\circ$ & $\circ$ & & $\circ$ & & & & & $\circ$ & & & & & \\
\hline$b c d$ & dme-miR-1017 & G & A & $A$ & $A$ & G & $\mathrm{C}$ & $T$ & $\mathrm{C}$ & $T$ & A & $\mathrm{C}$ & $\mathrm{C}$ & $C$ & $A$ & $A$ & $A$ & $\mathrm{C}$ & $\mathrm{T}$ & $\mathrm{C}$ & $A$ & $T$ & $\mathrm{C}$ & $C$ & & \\
\hline eve & $5^{\prime}(-1599) F$ & A & A & $A$ & $A$ & G & $\mathrm{C}$ & $T$ & G & $G$ & $\mathrm{C}$ & C & $\mathrm{T}$ & $G$ & $G$ & $\mathrm{~T}$ & $\mathrm{~T}$ & $\mathrm{~T}$ & $C$ & $T$ & $\mathrm{C}$ & $G$ & $\mathrm{C}$ & $T$ & & \\
\hline & coincidence & & $\circ$ & $\circ$ & $\circ$ & $\circ$ & $\circ$ & $\circ$ & & & & $\circ$ & & & & & & & & & & & $\circ$ & & & \\
\hline$b c d$ & dme-miR-79 & $\mathrm{T}$ & A & A & $A$ & G & $\mathrm{C}$ & $T$ & A & G & A & $\mathrm{T}$ & $\mathrm{T}$ & $A$ & $\mathrm{C}$ & $\mathrm{C}$ & $A$ & $A$ & $A$ & G & $C$ & $A$ & $\mathrm{~T}$ & & & \\
\hline
\end{tabular}


Citation: Takasaki S (2013) Roles of miRNAs in Early Embryonic Development of Drosophila melanogaster. Genetics 2: 122. doi:10.4172/21611041.1000122

\begin{tabular}{l|l}
\hline eve & $5^{\prime}(-1599) \mathrm{F}$ \\
\hline
\end{tabular}

coincidence

\begin{tabular}{l|l|l|l|l|l|l|l|l|l|l|l|l|l|l|l|l|l|l|l|l|l|} 
A & A & A & A & G & C & T & G & G & C & C & T & G & G & T & T & T & C & T & C & G & C \\
\hline
\end{tabular}

5'(-xxxx)F/R: xxxx-start position in 5' upstream, F-Forward strand, R-Reverse strand

Table 4(a). Relations between the miRNAs of bcd and the 5' upstream region of eve.

\begin{tabular}{|c|c|c|c|c|c|c|c|c|c|c|c|c|c|c|c|c|c|c|c|c|c|c|c|c|c|c|}
\hline gene & miRNA/5'region & 1 & 2 & 3 & 4 & 5 & 6 & 7 & 8 & 9 & 10 & 11 & 12 & 13 & 14 & 15 & 16 & 17 & 18 & 19 & 20 & 21 & 22 & 23 & 24 & 25 \\
\hline eve & dme-miR-315 & $\mathrm{T}$ & $T$ & $\mathrm{~T}$ & $\mathrm{~T}$ & G & $A$ & $\mathrm{~T}$ & $\mathrm{~T}$ & G & $\mathrm{T}$ & $\mathrm{T}$ & G & $\mathrm{C}$ & $\mathrm{T}$ & $\mathrm{C}$ & $A$ & $\mathrm{G}$ & A & A & A & G & $\mathrm{C}$ & & & \\
\hline$b c d$ & $5^{\prime}(-1664) \mathrm{F}$ & $\mathrm{T}$ & $T$ & $\mathrm{~T}$ & $\mathrm{~T}$ & G & A & A & $\mathrm{T}$ & A & $A$ & $A$ & $\mathrm{~T}$ & $\mathrm{~T}$ & $\mathrm{~T}$ & C & $\mathrm{T}$ & $A$ & $A$ & $A$ & A & $\mathrm{T}$ & $A$ & & & \\
\hline & coincidence & $\circ$ & $\circ$ & $\circ$ & $\circ$ & $\circ$ & $\circ$ & & $\circ$ & & & & & & $\circ$ & $\circ$ & & & $\circ$ & $\circ$ & $\circ$ & & & & & \\
\hline$b c d$ & $5^{\prime}(-249) R$ & $\mathrm{~T}$ & $\mathrm{~T}$ & $\mathrm{~T}$ & $\mathrm{~T}$ & G & A & G & $T$ & A & A & $\mathrm{T}$ & $\mathrm{T}$ & $\mathrm{T}$ & A & A & $A$ & $A$ & A & $\mathrm{T}$ & C & A & A & & & \\
\hline & coincidence & $\circ$ & $\circ$ & $\circ$ & $\circ$ & $\circ$ & $\circ$ & & $\circ$ & & & $\circ$ & & & & & o & & $\circ$ & & & & & & & \\
\hline
\end{tabular}

$5^{\prime}(-x x x x) F / R$ : xxxx-start position in 5' upstream, F-Forward strand, R-Reverse strand

Table 4(b). Relations between the miRNAs of eve and the 5' upstream region of bcd.

\begin{tabular}{|c|c|c|c|c|c|c|c|c|c|c|c|c|c|c|c|c|c|c|c|c|c|c|c|c|c|c|}
\hline gene & miRNA/5'region & 1 & 2 & 3 & 4 & 5 & 6 & 7 & 8 & 9 & 10 & 11 & 12 & 13 & 14 & 15 & 16 & 17 & 18 & 19 & 20 & 21 & 22 & 23 & 24 & 25 \\
\hline & hb dme-miR-989 & $\mathrm{T}$ & G & $\mathrm{T}$ & G & $A$ & $\mathrm{~T}$ & $\mathrm{G}$ & $\mathrm{T}$ & G & A & C & G & $\mathrm{T}$ & A & G & $\mathrm{T}$ & G & $\mathrm{G}$ & A & A & C & & & & \\
\hline \multirow[t]{2}{*}{ eve } & $5^{\prime}(-16) R$ & $\mathrm{~T}$ & G & $\mathrm{T}$ & $\mathrm{G}$ & A & $\mathrm{T}$ & $\mathrm{T}$ & $\mathrm{C}$ & $A$ & $A$ & $A$ & G & $\mathrm{T}$ & $\mathrm{T}$ & $\mathrm{G}$ & G & $\mathrm{C}$ & $\mathrm{T}$ & $\mathrm{T}$ & $A$ & $\mathrm{~T}$ & & & & \\
\hline & coincidence & $\circ$ & $\circ$ & $\circ$ & $\circ$ & $\circ$ & $\circ$ & & & & $\circ$ & & $\circ$ & $\circ$ & & $\circ$ & & & & & o & & & & & \\
\hline$h b$ & dme-miR-963 & A & $\mathrm{C}$ & A & $A$ & G & G & $\mathrm{T}$ & A & A & A & $\mathrm{T}$ & A & $\mathrm{T}$ & $\mathrm{C}$ & A & G & G & $\mathrm{T}$ & $\mathrm{T}$ & G & $\mathrm{T}$ & $\mathrm{T}$ & $\mathrm{T}$ & $\mathrm{C}$ & \\
\hline \multirow[t]{2}{*}{ eve } & $5^{\prime}(-3522) \mathrm{F}$ & $A$ & $\mathrm{C}$ & $A$ & $A$ & $G$ & $G$ & $\mathrm{~T}$ & $\mathrm{~T}$ & $A$ & $\mathrm{~T}$ & $A$ & $A$ & $\mathrm{C}$ & $G$ & $\mathrm{C}$ & $\mathrm{T}$ & $\mathrm{C}$ & $\mathrm{T}$ & $A$ & $C$ & $\mathrm{~T}$ & $\mathrm{~T}$ & $A$ & $C$ & \\
\hline & coincidence & $\circ$ & $\circ$ & $\circ$ & $\circ$ & $\circ$ & $\circ$ & $\circ$ & & $\circ$ & & & $\circ$ & & $\circ$ & & & & $\circ$ & & & $\circ$ & ० & & $\circ$ & \\
\hline \multirow[t]{2}{*}{ eve } & $5^{\prime}(-1903) \mathrm{F}$ & G & $\mathrm{C}$ & A & A & $G$ & G & $\mathrm{T}$ & $\mathrm{T}$ & G & $\mathrm{T}$ & $T$ & G & $\mathrm{C}$ & $\mathrm{T}$ & $T$ & $\mathrm{G}$ & $\mathrm{T}$ & G & G & G & $\mathrm{T}$ & A & G & $G$ & \\
\hline & coincidence & & $\circ$ & $\circ$ & $\circ$ & $\circ$ & $\circ$ & $\circ$ & & & & $\circ$ & & & & & & & & & $\circ$ & $\circ$ & & & & \\
\hline \multirow[t]{2}{*}{ eve } & $5^{\prime}(-2943) R$ & A & C & A & A & $G$ & $G$ & $\mathrm{~T}$ & A & $\mathrm{T}$ & $\mathrm{T}$ & $\mathrm{T}$ & $T$ & $\mathrm{~T}$ & $\mathrm{~T}$ & A & $A$ & C & $\mathrm{T}$ & C & $C$ & $G$ & C & C & $\mathrm{T}$ & \\
\hline & coincidence & $\circ$ & $\circ$ & $\circ$ & $\circ$ & $\circ$ & $\circ$ & $\circ$ & $\circ$ & & & $\circ$ & & $\circ$ & & $\circ$ & & & $\circ$ & & & & & & & \\
\hline$h b$ & dme-miR-8 & $\mathrm{T}$ & $A$ & $A$ & $\mathrm{~T}$ & $A$ & $\mathrm{C}$ & $\mathrm{T}$ & G & $T$ & C & A & G & G & $\mathrm{T}$ & A & $A$ & $A$ & G & A & $\mathrm{T}$ & $G$ & $\mathrm{~T}$ & C & & \\
\hline \multirow[t]{2}{*}{ eve } & $5^{\prime}(-4571) R$ & A & $A$ & $A$ & $\mathrm{~T}$ & $A$ & $\mathrm{C}$ & $\mathrm{T}$ & A & $\mathrm{C}$ & $\mathrm{T}$ & A & C & A & A & G & $A$ & A & $\mathrm{C}$ & A & $\mathrm{T}$ & $\mathrm{T}$ & A & $\mathrm{T}$ & & \\
\hline & coincidence & & $\circ$ & $\circ$ & $\circ$ & $\circ$ & $\circ$ & $\circ$ & & & & $\circ$ & & & & & $\circ$ & $\circ$ & & $\circ$ & $\circ$ & & & & & \\
\hline \multirow[t]{2}{*}{ eve } & $5^{\prime}(-2114) R$ & C & A & A & $\mathrm{T}$ & A & $\mathrm{C}$ & $\mathrm{T}$ & $\mathrm{C}$ & A & A & $T$ & C & $\mathrm{C}$ & $\mathrm{T}$ & C & $\mathrm{T}$ & A & $\mathrm{T}$ & C & $\mathrm{T}$ & $\mathrm{T}$ & C & C & & \\
\hline & coincidence & & $\circ$ & $\circ$ & $\circ$ & $\circ$ & $\circ$ & $\circ$ & & & & & & & $\circ$ & & & $\circ$ & & & $\circ$ & & & $\circ$ & & \\
\hline$h b$ & dme-miR-315 & $\mathrm{T}$ & $\mathrm{T}$ & $\mathrm{T}$ & $\mathrm{T}$ & G & $A$ & $\mathrm{~T}$ & $\mathrm{~T}$ & $\mathrm{G}$ & $\mathrm{T}$ & $\mathrm{T}$ & G & $\mathrm{C}$ & $\mathrm{T}$ & $\mathrm{C}$ & $A$ & G & $A$ & $A$ & $A$ & G & $\mathrm{C}$ & & & \\
\hline \multirow[t]{2}{*}{ eve } & $5^{\prime}(-4983) R$ & $\mathrm{~T}$ & $\mathrm{~T}$ & $\mathrm{~T}$ & $\mathrm{~T}$ & G & A & $\mathrm{T}$ & $\mathrm{T}$ & $\mathrm{C}$ & G & $\mathrm{T}$ & A & C & G & A & A & G & $\mathrm{T}$ & $\mathrm{T}$ & $\mathrm{T}$ & C & $\mathrm{T}$ & & & \\
\hline & coincidence & $\circ$ & $\circ$ & $\circ$ & $\circ$ & $\circ$ & $\circ$ & $\circ$ & $\circ$ & & & $\circ$ & & $\circ$ & & & $\circ$ & $\circ$ & & & & & & & & \\
\hline \multirow[t]{2}{*}{ eve } & $5^{\prime}(-4610) R$ & A & $\mathrm{T}$ & $\mathrm{T}$ & $\mathrm{T}$ & G & A & $\mathrm{T}$ & $\mathrm{T}$ & A & $\mathrm{T}$ & A & $\mathrm{T}$ & $\mathrm{T}$ & A & $\mathrm{T}$ & C & G & $\mathrm{T}$ & A & $\mathrm{T}$ & G & C & & & \\
\hline & coincidence & & $\circ$ & $\circ$ & $\circ$ & $\circ$ & $\circ$ & $\circ$ & $\circ$ & & $\circ$ & & & & & & & $\circ$ & & $\circ$ & & $\circ$ & $\circ$ & & & \\
\hline \multirow[t]{2}{*}{ eve } & $5^{\prime}(-3001) R$ & $A$ & $\mathrm{~T}$ & $\mathrm{~T}$ & $\mathrm{~T}$ & $G$ & $A$ & $\mathrm{~T}$ & $G$ & $A$ & $G$ & G & $A$ & $G$ & $A$ & $\mathrm{~T}$ & $A$ & $\mathrm{~T}$ & $\mathrm{~T}$ & A & $G$ & $A$ & G & & & \\
\hline & coincidence & & $\circ$ & $\circ$ & $\circ$ & $\circ$ & $\circ$ & $\circ$ & & & & & & & & & $\circ$ & & & $\circ$ & & & & & & \\
\hline \multirow[t]{2}{*}{ eve } & $5^{\prime}(-2884) R$ & C & $\mathrm{T}$ & $\mathrm{T}$ & $\mathrm{T}$ & $G$ & A & $\mathrm{T}$ & A & $\mathrm{T}$ & $\mathrm{T}$ & $\mathrm{T}$ & $C$ & $\mathrm{~T}$ & A & G & $\mathrm{T}$ & C & A & A & $\mathrm{T}$ & $\mathrm{T}$ & C & & & \\
\hline & coincidence & & $\circ$ & $\circ$ & $\circ$ & $\circ$ & $\circ$ & $\circ$ & & & $\circ$ & $\circ$ & & & & & & & $\circ$ & $\circ$ & & & $\circ$ & & & \\
\hline$h b$ & dme-miR-976 & $\mathrm{T}$ & $\mathrm{T}$ & G & $G$ & $A$ & $\mathrm{~T}$ & $\mathrm{~T}$ & A & G & $\mathrm{T}$ & $\mathrm{T}$ & A & $\mathrm{T}$ & C & A & $\mathrm{T}$ & $\mathrm{C}$ & A & A & $\mathrm{T}$ & G & $\mathrm{C}$ & & & \\
\hline \multirow[t]{2}{*}{ eve } & $5^{\prime}(-3250) \mathrm{F}$ & $A$ & $T$ & G & $G$ & $A$ & $\mathrm{~T}$ & $\mathrm{~T}$ & $\mathrm{~T}$ & $G$ & $T$ & G & $\mathrm{T}$ & $A$ & $A$ & G & C & $A$ & $\mathrm{~T}$ & $T$ & $A$ & $A$ & $A$ & & & \\
\hline & coincidence & & $\circ$ & $\circ$ & $\circ$ & $\circ$ & $\circ$ & $\circ$ & & $\circ$ & $\circ$ & & & & & & & & & & & & & & & \\
\hline \multirow[t]{2}{*}{ eve } & $5^{\prime}(-4523) R$ & G & $\mathrm{T}$ & G & G & A & $\mathrm{T}$ & $\mathrm{T}$ & $\mathrm{T}$ & $\mathrm{T}$ & A & $\mathrm{T}$ & $\mathrm{T}$ & A & C & C & G & $\mathrm{T}$ & $\mathrm{T}$ & $\mathrm{T}$ & C & $\mathrm{T}$ & $\mathrm{T}$ & & & \\
\hline & coincidence & & $\circ$ & $\circ$ & $\circ$ & $\circ$ & $\circ$ & $\circ$ & & & & $\circ$ & & & $\circ$ & & & & & & & & & & & \\
\hline & & & & & & & & & & & & & & & & & & & & & & & & & & \\
\hline
\end{tabular}


Citation: Takasaki S (2013) Roles of miRNAs in Early Embryonic Development of Drosophila melanogaster. Genetics 2: 122. doi:10.4172/21611041.1000122

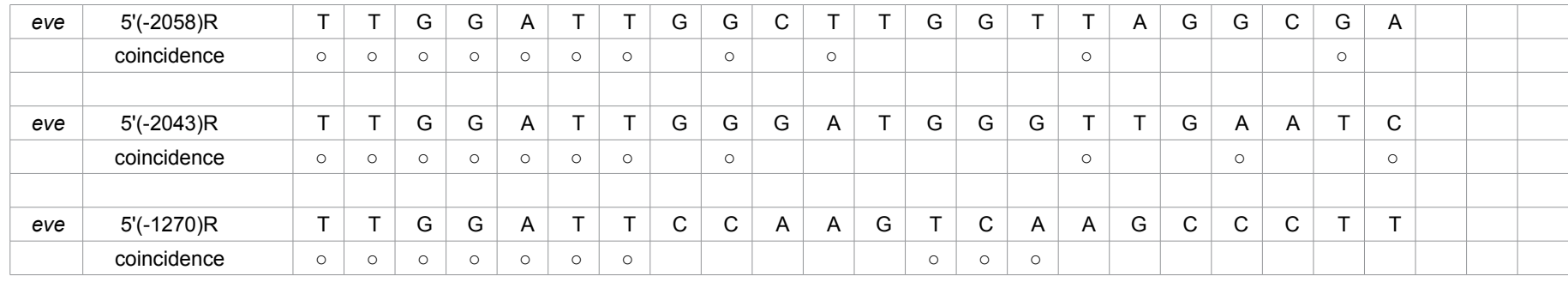

5'(-xxxx)F/R: xxxx-start position in 5' upstream, F-Forward strand, R-Reverse strand

Table 4(c). Relations between the miRNAs of $h b$ and the 5' upstream region of eve

\begin{tabular}{|c|c|c|c|c|c|c|c|c|c|c|c|c|c|c|c|c|c|c|c|c|c|c|c|c|c|c|}
\hline gene & miRNA/5'region & 1 & 2 & 3 & 4 & 5 & 6 & 7 & 8 & 9 & 10 & 11 & 12 & 13 & 14 & 15 & 16 & 17 & 18 & 19 & 20 & 21 & 22 & 23 & 24 & 25 \\
\hline eve & dme-miR-315 & $\mathrm{T}$ & $\mathrm{T}$ & $\mathrm{T}$ & $\mathrm{T}$ & G & A & $\mathrm{T}$ & $\mathrm{T}$ & G & $\mathrm{T}$ & $\mathrm{T}$ & G & C & $\mathrm{T}$ & C & A & G & A & A & A & G & C & & & \\
\hline$h b$ & $5^{\prime}(-961) R$ & C & $\mathrm{T}$ & $\mathrm{T}$ & $\mathrm{T}$ & G & A & $\mathrm{T}$ & $\mathrm{T}$ & $\mathrm{T}$ & G & C & G & $\mathrm{T}$ & A & G & $\mathrm{T}$ & $\mathrm{T}$ & $\mathrm{T}$ & $\mathrm{T}$ & $\mathrm{T}$ & C & $\mathrm{T}$ & & & \\
\hline & coincidence & & $\circ$ & $\circ$ & $\circ$ & $\circ$ & $\circ$ & $\circ$ & $\circ$ & & & & $\circ$ & & & & & & & & & & & & & \\
\hline$h b$ & $5^{\prime}(-3557) R$ & $\mathrm{~T}$ & $\mathrm{~T}$ & $\mathrm{~T}$ & $T$ & $G$ & A & $\mathrm{T}$ & A & G & C & A & G & $\mathrm{T}$ & $\mathrm{T}$ & A & C & G & $\mathrm{T}$ & $\mathrm{T}$ & $\mathrm{T}$ & C & G & & & \\
\hline & coincidence & $\circ$ & $\circ$ & ० & $\circ$ & $\circ$ & $\circ$ & $\circ$ & & $\circ$ & & & $\circ$ & & $\circ$ & & & $\circ$ & & & & & & & & \\
\hline
\end{tabular}

$5^{\prime}(-x x x x) F / R:$ xxxx-start position in $5^{\prime}$ upstream, F-Forward strand, R-Reverse strand

Table 4(d). Relations between the miRNAs of eve and the 5' upstream region of $h b$.

\begin{tabular}{|c|c|c|c|c|c|c|c|c|c|c|c|c|c|c|c|c|c|c|c|c|c|c|c|c|c|c|}
\hline gene & miRNA/5'region & 1 & 2 & 3 & 4 & 5 & 6 & 7 & 8 & 9 & 10 & 11 & 12 & 13 & 14 & 15 & 16 & 17 & 18 & 19 & 20 & 21 & 22 & 23 & 24 & 25 \\
\hline$K r$ & dme-miR-277 & $\mathrm{T}$ & $A$ & A & $A$ & $\mathrm{~T}$ & $\mathrm{G}$ & C & $A$ & C & $T$ & $A$ & $T$ & $C$ & $\mathrm{~T}$ & $G$ & $G$ & $\mathrm{~T}$ & $A$ & $C$ & G & $A$ & $\mathrm{C}$ & $A$ & & \\
\hline \multirow[t]{2}{*}{ eve } & $5^{\prime}(-3175) \mathrm{F}$ & $\mathrm{T}$ & A & A & $A$ & $\mathrm{~T}$ & G & C & A & G & C & $\mathrm{T}$ & A & A & $\mathrm{T}$ & $\mathrm{T}$ & C & G & $\mathrm{T}$ & C & G & A & $\mathrm{T}$ & $\mathrm{T}$ & & \\
\hline & coincidence & $\circ$ & $\circ$ & $\circ$ & $\circ$ & $\circ$ & $\circ$ & $\circ$ & $\circ$ & & & & & & $\circ$ & & & & & $\circ$ & $\circ$ & $\circ$ & & & & \\
\hline \multirow[t]{2}{*}{ eve } & $5^{\prime}(-2163) \mathrm{F}$ & A & $A$ & A & $A$ & $\mathrm{~T}$ & G & C & G & A & A & $A$ & G & $\mathrm{T}$ & G & $\mathrm{T}$ & $\mathrm{T}$ & $\mathrm{T}$ & G & $\mathrm{C}$ & G & G & A & $\mathrm{T}$ & & \\
\hline & coincidence & & $\circ$ & $\circ$ & $\circ$ & $\circ$ & $\circ$ & $\circ$ & & & & $\circ$ & & & & & & $\circ$ & & $\circ$ & $\circ$ & & & & & \\
\hline \multirow[t]{2}{*}{ eve } & $5^{\prime}(-2329) R$ & G & $A$ & A & A & $\mathrm{T}$ & G & C & $\mathrm{C}$ & G & G & C & A & A & A & G & A & $\mathrm{T}$ & $\mathrm{T}$ & C & G & C & A & A & & \\
\hline & coincidence & & $\circ$ & $\circ$ & $\circ$ & $\circ$ & $\circ$ & $\circ$ & & & & & & & & $\circ$ & & $\circ$ & & $\circ$ & $\circ$ & & & $\circ$ & & \\
\hline$K r$ & dme-miR-274 & $\mathrm{T}$ & $\mathrm{T}$ & $\mathrm{T}$ & $\mathrm{T}$ & $G$ & $\mathrm{~T}$ & G & $A$ & C & $\mathrm{C}$ & $G$ & $A$ & $C$ & $A$ & $\mathrm{C}$ & $\mathrm{T}$ & $A$ & $A$ & $\mathrm{C}$ & $G$ & G & $G$ & $\mathrm{~T}$ & $A$ & \\
\hline \multirow[t]{2}{*}{ eve } & $5^{\prime}(-4572) F$ & A & $\mathrm{T}$ & $\mathrm{T}$ & $\mathrm{T}$ & G & $\mathrm{T}$ & G & $\mathrm{T}$ & A & A & $\mathrm{T}$ & A & $\mathrm{T}$ & $\mathrm{T}$ & $\mathrm{T}$ & A & $\mathrm{T}$ & G & $\mathrm{T}$ & $\mathrm{T}$ & $\mathrm{T}$ & $\mathrm{T}$ & $\mathrm{T}$ & $\mathrm{T}$ & \\
\hline & coincidence & & $\circ$ & $\circ$ & $\circ$ & $\circ$ & $\circ$ & $\circ$ & & & & & $\circ$ & & & & & & & & & & & $\circ$ & & \\
\hline \multirow[t]{2}{*}{ eve } & $5^{\prime}(-4286) F$ & $\mathrm{~T}$ & $\mathrm{~T}$ & $\mathrm{~T}$ & $\mathrm{~T}$ & G & $\mathrm{T}$ & G & G & C & C & $\mathrm{T}$ & C & $\mathrm{T}$ & $\mathrm{T}$ & $\mathrm{T}$ & $\mathrm{T}$ & $\mathrm{T}$ & G & $\mathrm{T}$ & $\mathrm{T}$ & $\mathrm{T}$ & $\mathrm{C}$ & $\mathrm{G}$ & A & \\
\hline & coincidence & $\circ$ & $\circ$ & $\circ$ & $\circ$ & $\circ$ & $\circ$ & $\circ$ & & $\circ$ & $\circ$ & & & & & & $\circ$ & & & & & & & & $\circ$ & \\
\hline \multirow[t]{2}{*}{ eve } & $5^{\prime}(-3843) F$ & $\mathrm{~T}$ & $\mathrm{~T}$ & $\mathrm{~T}$ & $\mathrm{~T}$ & G & $\mathrm{T}$ & G & $\mathrm{C}$ & C & C & G & G & $\mathrm{T}$ & G & C & $\mathrm{T}$ & C & $\mathrm{T}$ & C & $\mathrm{T}$ & $\mathrm{T}$ & $\mathrm{T}$ & $A$ & $C$ & \\
\hline & coincidence & $\circ$ & $\circ$ & $\circ$ & $\circ$ & $\circ$ & $\circ$ & $\circ$ & & $\circ$ & $\circ$ & $\circ$ & & & & $\circ$ & $\circ$ & & & $\circ$ & & & & & & \\
\hline \multirow[t]{2}{*}{ eve } & $5^{\prime}(-3448) \mathrm{F}$ & G & $\mathrm{T}$ & $\mathrm{T}$ & $\mathrm{T}$ & G & $\mathrm{T}$ & G & $\mathrm{T}$ & $\mathrm{T}$ & $\mathrm{T}$ & $\mathrm{G}$ & $\mathrm{T}$ & $\mathrm{T}$ & $\mathrm{T}$ & G & $\mathrm{T}$ & $\mathrm{T}$ & C & $\mathrm{G}$ & $\mathrm{C}$ & G & A & $\mathrm{T}$ & G & \\
\hline & coincidence & & $\circ$ & $\circ$ & $\circ$ & $\circ$ & $\circ$ & $\circ$ & & & & $\circ$ & & & & & $\circ$ & & & & & ० & & $\circ$ & & \\
\hline \multirow[t]{2}{*}{ eve } & $5^{\prime}(-3246) \mathrm{F}$ & A & $\mathrm{T}$ & $\mathrm{T}$ & $\mathrm{T}$ & G & $\mathrm{T}$ & G & $\mathrm{T}$ & A & A & $\mathrm{G}$ & $\mathrm{C}$ & A & $\mathrm{T}$ & $\mathrm{T}$ & A & A & A & $A$ & A & C & G & C & G & \\
\hline & coincidence & & $\circ$ & $\circ$ & $\circ$ & $\circ$ & $\circ$ & $\circ$ & & & & $\circ$ & & & & & & $\circ$ & $\circ$ & & & & $\circ$ & & & \\
\hline \multirow[t]{2}{*}{ eve } & $5^{\prime}(-2590) \mathrm{F}$ & $\mathrm{T}$ & $\mathrm{T}$ & $\mathrm{T}$ & $\mathrm{T}$ & G & $\mathrm{T}$ & G & $\mathrm{T}$ & A & $A$ & $A$ & $A$ & A & $A$ & C & $T$ & G & A & $A$ & C & $T$ & G & $\mathrm{G}$ & $\mathrm{C}$ & \\
\hline & coincidence & $\circ$ & $\circ$ & $\circ$ & $\circ$ & $\circ$ & $\circ$ & $\circ$ & & & & & $\circ$ & & $\circ$ & $\circ$ & $\circ$ & & $\circ$ & & & & $\circ$ & & & \\
\hline \multirow[t]{2}{*}{ eve } & $5^{\prime}(-2246) \mathrm{F}$ & $\mathrm{C}$ & $\mathrm{T}$ & $\mathrm{T}$ & $\mathrm{T}$ & G & $\mathrm{T}$ & G & $A$ & G & $\mathrm{T}$ & $\mathrm{G}$ & C & A & G & $A$ & A & $T$ & G & $\mathrm{T}$ & G & C & A & $A$ & $\mathrm{~T}$ & \\
\hline & coincidence & & $\circ$ & $\circ$ & $\circ$ & $\circ$ & $\circ$ & $\circ$ & $\circ$ & & & $\circ$ & & & & & & & & & $\circ$ & & & & & \\
\hline \multirow[t]{2}{*}{ eve } & $5^{\prime}(-4355) R$ & C & $\mathrm{T}$ & $\mathrm{T}$ & $\mathrm{T}$ & G & $\mathrm{T}$ & G & $\mathrm{C}$ & G & G & C & $\mathrm{C}$ & $\mathrm{C}$ & $A$ & $A$ & $\mathrm{~T}$ & G & $A$ & $\mathrm{~T}$ & $\mathrm{~T}$ & A & G & $\mathrm{C}$ & $\mathrm{G}$ & \\
\hline & coincidence & & $\circ$ & $\circ$ & $\circ$ & $\circ$ & $\circ$ & $\circ$ & & & & & & & $\circ$ & & $\circ$ & & $\circ$ & & & & $\circ$ & & & \\
\hline$K r$ & dme-miR-305 & A & $\mathrm{T}$ & $\mathrm{T}$ & G & $\mathrm{T}$ & $A$ & C & $\mathrm{T}$ & $\mathrm{T}$ & C & $A$ & $\mathrm{~T}$ & $\mathrm{C}$ & $A$ & G & G & $T$ & G & $\mathrm{C}$ & $\mathrm{T}$ & C & $\mathrm{T}$ & $\mathrm{G}$ & & \\
\hline \multirow[t]{2}{*}{ eve } & $5^{\prime}(-4679) R$ & A & $\mathrm{T}$ & $\mathrm{T}$ & $\mathrm{G}$ & $\mathrm{T}$ & $A$ & C & $A$ & $\mathrm{~T}$ & G & $\mathrm{C}$ & C & $T$ & $\mathrm{C}$ & C & $\mathrm{T}$ & $T$ & $\mathrm{~T}$ & $A$ & A & $T$ & $\mathrm{C}$ & $\mathrm{C}$ & & \\
\hline & coincidence & $\circ$ & $\circ$ & $\circ$ & $\circ$ & $\circ$ & $\circ$ & $\circ$ & & $\circ$ & & & & & & & & $\circ$ & & & & & & & & \\
\hline \multirow[t]{2}{*}{ eve } & $5^{\prime}(-4632) R$ & $\mathrm{~T}$ & $\mathrm{~T}$ & $\mathrm{~T}$ & G & $\mathrm{T}$ & $A$ & C & $\mathrm{T}$ & $\mathrm{T}$ & $\mathrm{T}$ & $\mathrm{T}$ & A & $\mathrm{T}$ & $\mathrm{C}$ & A & $\mathrm{T}$ & A & $\mathrm{T}$ & $\mathrm{T}$ & $\mathrm{T}$ & G & G & $A$ & & \\
\hline & coincidence & & $\circ$ & $\circ$ & $\circ$ & $\circ$ & $\circ$ & $\circ$ & $\circ$ & $\circ$ & & & & & & & & & & & $\circ$ & & & & & \\
\hline$K r$ & dme-miR-315 & $\mathrm{T}$ & $T$ & $T$ & $T$ & $G$ & $A$ & $\mathrm{~T}$ & $T$ & $G$ & $T$ & $\mathrm{~T}$ & $G$ & $\mathrm{C}$ & $T$ & $\mathrm{C}$ & $A$ & $G$ & $A$ & $A$ & A & $G$ & $\mathrm{C}$ & & & \\
\hline \multirow[t]{2}{*}{ eve } & $5^{\prime}(-4983) R$ & $\mathrm{~T}$ & $\mathrm{~T}$ & $\mathrm{~T}$ & $\mathrm{~T}$ & G & $A$ & $\mathrm{~T}$ & $\mathrm{~T}$ & C & G & $\mathrm{T}$ & A & C & G & A & A & G & $\mathrm{T}$ & $\mathrm{T}$ & $\mathrm{T}$ & C & $\mathrm{T}$ & & & \\
\hline & coincidence & $\circ$ & $\circ$ & $\circ$ & $\circ$ & $\circ$ & $\circ$ & $\circ$ & $\circ$ & & & $\circ$ & & $\circ$ & & & $\circ$ & $\circ$ & & & & & & & & \\
\hline \multirow[t]{2}{*}{ eve } & $5^{\prime}(-4610) R$ & A & $\mathrm{T}$ & $\mathrm{T}$ & $\mathrm{T}$ & G & A & $\mathrm{T}$ & $\mathrm{T}$ & A & $\mathrm{T}$ & A & $\mathrm{T}$ & $\mathrm{T}$ & A & $\mathrm{T}$ & C & G & $\mathrm{T}$ & A & $\mathrm{T}$ & G & $\mathrm{C}$ & & & \\
\hline & coincidence & & $\circ$ & $\circ$ & $\circ$ & $\circ$ & $\circ$ & $\circ$ & $\circ$ & & $\circ$ & & & & & & & $\circ$ & & $\circ$ & & $\circ$ & $\circ$ & & & \\
\hline \multirow[t]{2}{*}{ eve } & $5^{\prime}(-3001) R$ & A & $\mathrm{T}$ & $\mathrm{T}$ & $\mathrm{T}$ & G & A & $\mathrm{T}$ & G & A & G & G & A & G & A & $\mathrm{T}$ & A & $\mathrm{T}$ & $\mathrm{T}$ & A & G & A & G & & & \\
\hline & coincidence & & $\circ$ & $\circ$ & $\circ$ & $\circ$ & $\circ$ & $\circ$ & & & & & & & & & $\circ$ & & & $\circ$ & & & & & & \\
\hline
\end{tabular}


Citation: Takasaki S (2013) Roles of miRNAs in Early Embryonic Development of Drosophila melanogaster. Genetics 2: 122. doi:10.4172/21611041.1000122

\begin{tabular}{|c|c|c|c|c|c|c|c|c|c|c|c|c|c|c|c|c|c|c|c|c|c|c|c|c|c|c|}
\hline eve & $5^{\prime}(-2884) R$ & $C$ & $\mathrm{~T}$ & $\mathrm{~T}$ & $\mathrm{~T}$ & $G$ & $A$ & $\mathrm{~T}$ & A & $\mathrm{T}$ & $\mathrm{T}$ & $\mathrm{T}$ & $C$ & $\mathrm{~T}$ & A & G & $T$ & $C$ & A & A & $\mathrm{T}$ & $\mathrm{T}$ & $C$ & & & \\
\hline & coincidence & & $\circ$ & 0 & $\circ$ & $\circ$ & $\circ$ & o & & & $\circ$ & $\circ$ & & & & & & & $\circ$ & $\circ$ & & & $\circ$ & & & \\
\hline$K r$ & dme-miR-263b & C & $T$ & $\mathrm{~T}$ & G & G & C & A & C & $\mathrm{T}$ & G & G & G & A & G & A & A & $\mathrm{T}$ & $\mathrm{T}$ & C & A & C & & & & \\
\hline \multirow[t]{2}{*}{ eve } & $5^{\prime}(-2682) R$ & $\mathrm{~T}$ & $\mathrm{~T}$ & $\mathrm{~T}$ & G & G & C & A & A & A & C & C & $\mathrm{T}$ & A & $\mathrm{T}$ & $\mathrm{T}$ & $\mathrm{T}$ & C & A & G & A & A & & & & \\
\hline & coincidence & & $\circ$ & o & $\circ$ & $\circ$ & $\circ$ & $\circ$ & & & & & & $\circ$ & & & & & & & $\circ$ & & & & & \\
\hline \multirow[t]{2}{*}{ eve } & $5^{\prime}(-2390) R$ & A & $T$ & $\mathrm{~T}$ & G & G & $C$ & A & A & $T$ & A & A & A & A & C & G & G & C & G & A & A & A & & & & \\
\hline & coincidence & & $\circ$ & $\circ$ & $\circ$ & $\circ$ & $\circ$ & $\circ$ & & $\circ$ & & & & $\circ$ & & & & & & & $\circ$ & & & & & \\
\hline \multirow[t]{2}{*}{ eve } & $5^{\prime}(-1720) R$ & A & $\mathrm{T}$ & $\mathrm{T}$ & G & G & $C$ & A & $\mathrm{T}$ & $\mathrm{T}$ & A & A & C & $\mathrm{T}$ & C & G & C & C & C & G & G & C & & & & \\
\hline & coincidence & & $\circ$ & $\circ$ & $\circ$ & $\circ$ & $\circ$ & $\circ$ & & $\circ$ & & & & & & & & & & & & $\circ$ & & & & \\
\hline$K r$ & dme-miR-316 & $T$ & G & $\mathrm{T}$ & $C$ & $T$ & $T$ & $T$ & $T$ & $T$ & $C$ & $C$ & G & $C$ & $T$ & $T$ & A & C & $T$ & G & G & C & G & & & \\
\hline \multirow[t]{2}{*}{ eve } & $5^{\prime}(-2883) F$ & A & G & $\mathrm{T}$ & C & $\mathrm{T}$ & $\mathrm{T}$ & $\mathrm{T}$ & $\mathrm{T}$ & $\mathrm{T}$ & G & $\mathrm{T}$ & A & $\mathrm{T}$ & $\mathrm{T}$ & G & A & A & G & C & G & A & G & & & \\
\hline & coincidence & & $\circ$ & $\circ$ & $\circ$ & $\circ$ & $\circ$ & $\circ$ & $\circ$ & $\circ$ & & & & & $\circ$ & & $\circ$ & & & & $\circ$ & & $\circ$ & & & \\
\hline \multirow[t]{2}{*}{ eve } & $5^{\prime}(-4396) R$ & $C$ & G & $\mathrm{T}$ & $C$ & $T$ & $T$ & $T$ & $T$ & $T$ & G & G & A & $C$ & G & G & $C$ & $C$ & G & G & G & G & A & & & \\
\hline & coincidence & & $\circ$ & $\circ$ & $\circ$ & $\circ$ & $\circ$ & $\circ$ & $\circ$ & $\circ$ & & & & & & & & & & & $\circ$ & & & & & \\
\hline \multirow[t]{2}{*}{ eve } & $5^{\prime}(-1929) R$ & $\mathrm{~T}$ & G & $\mathrm{T}$ & $C$ & $T$ & $\mathrm{~T}$ & $T$ & G & A & $\mathrm{C}$ & $\mathrm{T}$ & $\mathrm{C}$ & $\mathrm{C}$ & G & $T$ & C & C & G & G & A & G & A & & & \\
\hline & coincidence & $\circ$ & $\circ$ & $\circ$ & $\circ$ & $\circ$ & $\circ$ & $\circ$ & & & $\circ$ & & & $\circ$ & & $\circ$ & & $\circ$ & & $\circ$ & & & & & & \\
\hline$K r$ & dme-miR-1011 & $\mathrm{T}$ & $\mathrm{T}$ & A & $\mathrm{T}$ & $\mathrm{T}$ & G & G & $\mathrm{T}$ & $\mathrm{T}$ & C & A & A & A & $\mathrm{T}$ & C & G & C & $\mathrm{T}$ & C & G & C & A & G & & \\
\hline \multirow[t]{2}{*}{ eve } & $5^{\prime}(-3977) \mathrm{F}$ & $T$ & $T$ & A & $T$ & $T$ & $G$ & G & $T$ & G & $\mathrm{C}$ & A & $\mathrm{C}$ & $\mathrm{C}$ & $T$ & $T$ & C & G & G & $\mathrm{C}$ & G & G & A & A & & \\
\hline & coincidence & $\circ$ & $\circ$ & $\circ$ & $\circ$ & $\circ$ & $\circ$ & $\circ$ & $\circ$ & & $\circ$ & $\circ$ & & & $\circ$ & & & & & $\circ$ & $\circ$ & & $\circ$ & & & \\
\hline \multirow[t]{2}{*}{ eve } & $5^{\prime}(-3357) F$ & $\mathrm{~T}$ & $\mathrm{~T}$ & A & $\mathrm{T}$ & $\mathrm{T}$ & G & G & A & A & A & $\mathrm{T}$ & $\mathrm{T}$ & $\mathrm{T}$ & C & A & $\mathrm{T}$ & $\mathrm{T}$ & G & G & G & $\mathrm{T}$ & C & G & & \\
\hline & coincidence & $\circ$ & $\circ$ & $\circ$ & $\circ$ & $\circ$ & $\circ$ & $\circ$ & & & & & & & & & & & & & $\circ$ & & & $\circ$ & & \\
\hline \multirow[t]{2}{*}{ eve } & $5^{\prime}(-2602) F$ & $T$ & $T$ & A & $T$ & $T$ & $G$ & G & A & C & $\mathrm{C}$ & $A$ & $A$ & $\mathrm{~T}$ & $T$ & $T$ & $T$ & G & $\mathrm{T}$ & G & $T$ & A & A & A & & \\
\hline & coincidence & $\circ$ & $\circ$ & $\circ$ & $\circ$ & $\circ$ & $\circ$ & $\circ$ & & & $\circ$ & $\circ$ & $\circ$ & & $\circ$ & & & & $\circ$ & & & & $\circ$ & & & \\
\hline \multirow[t]{2}{*}{ eve } & $5^{\prime}(-1689) R$ & $\mathrm{~T}$ & $T$ & A & $T$ & $T$ & $G$ & G & G & $T$ & $\mathrm{~T}$ & A & $\mathrm{T}$ & A & $T$ & $T$ & G & C & G & C & C & C & G & C & & \\
\hline & coincidence & $\circ$ & $\circ$ & $\circ$ & $\circ$ & $\circ$ & $\circ$ & $\circ$ & & $\circ$ & & $\circ$ & & $\circ$ & $\circ$ & & $\circ$ & $\circ$ & & $\circ$ & & $\circ$ & & & & \\
\hline$K r$ & dme-miR-283 & $\mathrm{T}$ & A & A & A & $\mathrm{T}$ & A & $T$ & C & A & G & C & $\mathrm{T}$ & G & G & $T$ & A & A & $\mathrm{T}$ & $\mathrm{T}$ & C & $\mathrm{T}$ & & & & \\
\hline \multirow[t]{2}{*}{ eve } & $5^{\prime}(-4650) F$ & $C$ & A & A & A & $\mathrm{T}$ & A & $T$ & G & A & $\mathrm{T}$ & A & A & A & A & G & $T$ & A & C & A & A & A & & & & \\
\hline & coincidence & & $\circ$ & $\circ$ & $\circ$ & $\circ$ & $\circ$ & $\circ$ & & $\circ$ & & & & & & & & $\circ$ & & & & & & & & \\
\hline \multirow[t]{2}{*}{ eve } & $5^{\prime}(-2893) F$ & G & A & A & A & $\mathrm{T}$ & A & $\mathrm{T}$ & C & A & A & A & G & $\mathrm{T}$ & C & $\mathrm{T}$ & $\mathrm{T}$ & $\mathrm{T}$ & $\mathrm{T}$ & $\mathrm{T}$ & G & $\mathrm{T}$ & & & & \\
\hline & coincidence & & $\circ$ & $\circ$ & $\circ$ & $\circ$ & $\circ$ & $\circ$ & $\circ$ & $\circ$ & & & & & & $\circ$ & & & $\circ$ & $\circ$ & & $\circ$ & & & & \\
\hline \multirow[t]{2}{*}{ eve } & $5^{\prime}(-619) \mathrm{F}$ & $C$ & A & A & A & $\mathrm{T}$ & A & $\mathrm{T}$ & A & $\mathrm{T}$ & A & G & $\mathrm{T}$ & G & G & G & A & $T$ & A & $C$ & A & $C$ & & & & \\
\hline & coincidence & & $\circ$ & $\circ$ & $\circ$ & $\circ$ & $\circ$ & $\circ$ & & & & & $\circ$ & $\circ$ & $\circ$ & & $\circ$ & & & & & & & & & \\
\hline \multirow[t]{2}{*}{ eve } & $5^{\prime}(-4558) R$ & $\mathrm{~T}$ & A & A & A & $\mathrm{T}$ & A & $T$ & $T$ & A & $C$ & A & $C$ & A & A & A & $T$ & A & $C$ & $\mathrm{~T}$ & A & C & & & & \\
\hline & coincidence & $\circ$ & $\circ$ & o & $\circ$ & $\circ$ & $\circ$ & $\circ$ & & $\circ$ & & & & & & & & $\circ$ & & $\circ$ & & & & & & \\
\hline
\end{tabular}

Table 4(e). Relations between the miRNAs of $K r$ and the 5 ' upstream region of eve.

\begin{tabular}{|c|c|c|c|c|c|c|c|c|c|c|c|c|c|c|c|c|c|c|c|c|c|c|c|c|c|c|}
\hline gene & miRNA/5'region & 1 & 2 & 3 & 4 & 5 & 6 & 7 & 8 & 9 & 10 & 11 & 12 & 13 & 14 & 15 & 16 & 17 & 18 & 19 & 20 & 21 & 22 & 23 & 24 & 25 \\
\hline eve & dme-miR-315 & $\mathrm{T}$ & $T$ & $T$ & $T$ & $\mathrm{G}$ & A & $\mathrm{T}$ & $T$ & $\mathrm{G}$ & $\mathrm{T}$ & $\mathrm{T}$ & G & $C$ & $\mathrm{~T}$ & C & A & $\mathrm{G}$ & A & A & A & G & C & & & \\
\hline \multirow[t]{2}{*}{$K r$} & $5^{\prime}(-3608) \mathrm{F}$ & A & $T$ & $T$ & $\mathrm{~T}$ & $G$ & A & $\mathrm{T}$ & $A$ & $A$ & $\mathrm{~T}$ & $\mathrm{~T}$ & $\mathrm{~T}$ & $G$ & C & A & $\mathrm{T}$ & $G$ & $\mathrm{~T}$ & C & A & C & $\mathrm{T}$ & & & \\
\hline & coincidence & & $\circ$ & 0 & 0 & $\circ$ & $\circ$ & $\circ$ & & & $\circ$ & $\circ$ & & & & & & $\circ$ & & & $\circ$ & & & & & \\
\hline & & & & & & & & & & & & & & & & & & & & & & & & & & \\
\hline \multirow[t]{2}{*}{ Kr } & $5^{\prime}(-3258) \mathrm{F}$ & A & $T$ & $T$ & $T$ & $G$ & A & $\mathrm{T}$ & $G$ & $G$ & $G$ & A & A & A & A & $T$ & $G$ & A & A & $\mathrm{T}$ & $T$ & A & $G$ & & & \\
\hline & coincidence & & o & $\circ$ & o & o & $\circ$ & $\circ$ & & $\circ$ & & & & & & & & & o & & & & & & & \\
\hline & & & & & & & & & & & & & & & & & & & & & & & & & & \\
\hline \multirow[t]{2}{*}{ Kr } & $5^{\prime}(-2923) \mathrm{F}$ & $G$ & $T$ & $T$ & $\mathrm{~T}$ & $G$ & A & $\mathrm{T}$ & $A$ & $\mathrm{~T}$ & $\mathrm{~T}$ & $\mathrm{~T}$ & $\mathrm{~T}$ & $T$ & $T$ & $T$ & $G$ & A & $\mathrm{T}$ & C & $G$ & C & $G$ & & & \\
\hline & coincidence & & o & o & o & o & o & $\circ$ & & & $\circ$ & $\circ$ & & & $\circ$ & & & & & & & & & & & \\
\hline & & & & & & & & & & & & & & & & & & & & & & & & & & \\
\hline \multirow[t]{2}{*}{ Kr } & $5^{\prime}(-2913) \mathrm{F}$ & $T$ & $T$ & $\mathrm{~T}$ & $\mathrm{~T}$ & $G$ & A & $\mathrm{T}$ & $C$ & G & C & G & $\mathrm{T}$ & $G$ & C & C & A & $\mathrm{T}$ & $G$ & G & G & $T$ & A & & & \\
\hline & coincidence & $\circ$ & o & $\circ$ & $\circ$ & $\circ$ & $\circ$ & $\circ$ & & $\circ$ & & & & & & $\circ$ & $\circ$ & & & & & & & & & \\
\hline & & & & & & & & & & & & & & & & & & & & & & & & & & \\
\hline \multirow[t]{2}{*}{ Kr } & $5^{\prime}(-2332) \mathrm{F}$ & C & $T$ & $T$ & $T$ & $G$ & A & $T$ & $G$ & A & C & A & A & $\mathrm{C}$ & C & C & $\mathrm{T}$ & $C$ & $G$ & $\mathrm{~T}$ & $T$ & $T$ & $\mathrm{~T}$ & & & \\
\hline & coincidence & & $\circ$ & $\circ$ & $\circ$ & $\circ$ & $\circ$ & $\circ$ & & & & & & $\circ$ & & $\circ$ & & & & & & & & & & \\
\hline & & & & & & & & & & & & & & & & & & & & & & & & & & \\
\hline \multirow[t]{2}{*}{ Kr } & $5^{\prime}(-1998) F$ & C & $T$ & $T$ & $T$ & $G$ & A & $\mathrm{T}$ & A & $C$ & $T$ & A & $T$ & $T$ & $C$ & $T$ & $A$ & G & $\mathrm{T}$ & $\mathrm{T}$ & $T$ & A & G & & & \\
\hline & coincidence & & $\circ$ & $\circ$ & $\circ$ & $\circ$ & $\circ$ & $\circ$ & & & $\circ$ & & & & & & $\circ$ & $\circ$ & & & & & & & & \\
\hline & & & & & & & & & & & & & & & & & & & & & & & & & & \\
\hline \multirow[t]{2}{*}{ Kr } & $5^{\prime}(-3081) R$ & $\mathrm{C}$ & $T$ & $T$ & $\mathrm{~T}$ & $G$ & $A$ & $T$ & $T$ & $G$ & $C$ & $\mathrm{~T}$ & $G$ & $A$ & $T$ & $C$ & $T$ & $G$ & $T$ & A & $T$ & A & G & & & \\
\hline & coincidence & & o & o & o & o & o & 0 & $\circ$ & $\circ$ & & $\circ$ & $\circ$ & & $\circ$ & o & & o & & o & & & & & & \\
\hline
\end{tabular}


Citation: Takasaki S (2013) Roles of miRNAs in Early Embryonic Development of Drosophila melanogaster. Genetics 2: 122. doi:10.4172/21611041.1000122

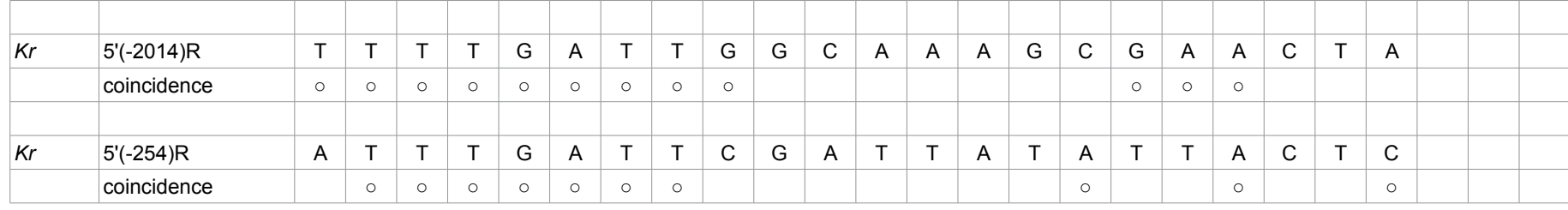

$5^{\prime}(-x x x x) F / R$ : xxxx-start position in $5^{\prime}$ upstream, F-Forward strand, R-Reverse strand

Table 4(f). Relations between the miRNAs of eve and the 5' upstream region of $\mathrm{Kr}$.

\begin{tabular}{|c|c|c|c|c|c|c|c|c|c|c|c|c|c|c|c|c|c|c|c|c|c|c|c|c|c|c|}
\hline gene & mi RNA/5'region & 1 & 2 & 3 & 4 & 5 & 6 & 7 & 8 & 9 & 10 & 11 & 12 & 13 & 14 & 15 & 16 & 17 & 18 & 19 & 20 & 21 & 22 & 23 & 24 & 25 \\
\hline$g t$ & Dme-miR-999 & $T$ & G & $\mathrm{T}$ & $T$ & A & A & C & $\mathrm{T}$ & G & $\mathrm{T}$ & A & A & G & A & C & $\mathrm{T}$ & G & $T$ & G & $\mathrm{T}$ & C & $T$ & & & \\
\hline \multirow[t]{2}{*}{ eve } & $5^{\prime}(-1567) F$ & $\mathrm{~T}$ & G & $\mathrm{T}$ & $\mathrm{T}$ & A & A & $T$ & C & C & G & $\mathrm{T}$ & $\mathrm{T}$ & $\mathrm{T}$ & G & C & C & A & $\mathrm{T}$ & C & A & G & C & & & \\
\hline & coincidence & $\mathrm{O}$ & $\mathrm{O}$ & O & $\mathrm{O}$ & $\mathrm{O}$ & $\mathrm{O}$ & & & & & & & & & 0 & & & $\mathrm{O}$ & & & & & & & \\
\hline \multirow[t]{2}{*}{ eve } & $5^{\prime}(-699) \mathrm{F}$ & $T$ & G & $\mathrm{T}$ & $\mathrm{T}$ & $A$ & A & A & $\mathrm{C}$ & G & $\mathrm{T}$ & G & $\mathrm{C}$ & G & G & $\mathrm{C}$ & $A$ & $T$ & $A$ & $\mathrm{~T}$ & A & $\mathrm{T}$ & $T$ & & & \\
\hline & coincidence & $\circ$ & $\circ$ & $\circ$ & $\circ$ & $\circ$ & $\circ$ & & & $\circ$ & $\circ$ & & & $\circ$ & & $\circ$ & & & & & & & $\circ$ & & & \\
\hline$g t$ & dme-miR-1014 & A & A & A & A & $\mathrm{T}$ & $\mathrm{T}$ & C & A & $\mathrm{T}$ & $\mathrm{T}$ & $\mathrm{T}$ & $\mathrm{T}$ & C & A & $\mathrm{T}$ & $\mathrm{T}$ & $\mathrm{T}$ & G & C & A & G & & & & \\
\hline \multirow[t]{2}{*}{ eve } & $5^{\prime}(-4657) \mathrm{F}$ & $\mathrm{C}$ & A & A & A & $\mathrm{T}$ & $T$ & C & $\mathrm{C}$ & A & A & A & $\mathrm{T}$ & A & $T$ & G & A & $\mathrm{T}$ & A & A & A & A & & & & \\
\hline & coincidence & & $\circ$ & $\circ$ & $\circ$ & $\circ$ & $\circ$ & $\circ$ & & & & & $\circ$ & & & & & $\circ$ & & & $\circ$ & & & & & \\
\hline \multirow[t]{2}{*}{ eve } & $5^{\prime}(-4054) R$ & G & A & A & A & $\mathrm{T}$ & $T$ & C & G & $A$ & G & C & $G$ & G & G & C & $A$ & A & $\mathrm{T}$ & A & A & A & & & & \\
\hline & coincidence & & $\circ$ & $\circ$ & $\circ$ & $\circ$ & $\circ$ & $\circ$ & & & & & & & & & & & & & $\circ$ & & & & & \\
\hline \multirow[t]{2}{*}{ eve } & $5^{\prime}(-2765) R$ & A & $A$ & $A$ & A & $\mathrm{T}$ & $T$ & C & $\mathrm{T}$ & G & $\mathrm{T}$ & $T$ & G & $A$ & $C$ & $\mathrm{~T}$ & $\mathrm{~T}$ & G & $\mathrm{C}$ & $T$ & $\mathrm{~T}$ & A & & & & \\
\hline & coincidence & $\circ$ & o & $\circ$ & $\circ$ & $\circ$ & $\circ$ & $\circ$ & & & $\circ$ & $\circ$ & & & & $\circ$ & $\circ$ & & & & & & & & & \\
\hline$g t$ & dme-miR-1006 & $\mathrm{T}$ & A & A & A & $\mathrm{T}$ & $\mathrm{T}$ & C & G & A & $\mathrm{T}$ & $\mathrm{T}$ & $\mathrm{T}$ & C & $\mathrm{T}$ & $\mathrm{T}$ & A & $\mathrm{T}$ & $\mathrm{T}$ & C & A & $\mathrm{T}$ & A & G & & \\
\hline \multirow[t]{2}{*}{ eve } & $5^{\prime}(-4657) \mathrm{F}$ & $\mathrm{C}$ & A & A & A & $\mathrm{T}$ & $\mathrm{T}$ & $\mathrm{C}$ & $\mathrm{C}$ & $A$ & A & A & $\mathrm{T}$ & $A$ & $\mathrm{~T}$ & G & $A$ & $\mathrm{~T}$ & A & A & A & A & G & $\mathrm{T}$ & & \\
\hline & coincidence & & $\circ$ & $\circ$ & $\circ$ & $\circ$ & $\circ$ & $\circ$ & & $\circ$ & & & $\circ$ & & $\circ$ & & $\circ$ & $\circ$ & & & $\circ$ & & & & & \\
\hline \multirow[t]{2}{*}{ eve } & $5^{\prime}(-4054) R$ & G & $A$ & A & A & $\mathrm{T}$ & $T$ & C & G & $A$ & G & C & G & G & G & C & $A$ & A & $\mathrm{T}$ & A & A & A & $\mathrm{C}$ & $\mathrm{T}$ & & \\
\hline & coincidence & & $\circ$ & $\circ$ & $\circ$ & $\circ$ & $\circ$ & $\circ$ & $\circ$ & $\circ$ & & & & & & & $\circ$ & & $\circ$ & & $\circ$ & & & & & \\
\hline \multirow[t]{2}{*}{ eve } & $5^{\prime}(-2766) R$ & A & $A$ & $A$ & A & $\mathrm{T}$ & $T$ & $\mathrm{C}$ & $\mathrm{T}$ & G & $\mathrm{T}$ & $T$ & G & $A$ & C & $\mathrm{T}$ & $\mathrm{T}$ & G & $\mathrm{C}$ & $T$ & $\mathrm{~T}$ & A & $A$ & $\mathrm{~T}$ & & \\
\hline & coincidence & & $\circ$ & $\circ$ & $\circ$ & $\circ$ & $\circ$ & $\circ$ & & & $\circ$ & $\circ$ & & & & $\circ$ & & & & & & & $\circ$ & & & \\
\hline$g t$ & dme-miR-10-3p & C & A & A & A & $\mathrm{T}$ & $T$ & C & G & $G$ & $\mathrm{~T}$ & $\mathrm{~T}$ & $\mathrm{~T}$ & C & $T$ & A & $G$ & A & G & A & $G$ & G & $T$ & $\mathrm{~T}$ & $\mathrm{~T}$ & \\
\hline \multirow[t]{2}{*}{ eve } & $5^{\prime}(-4657) \mathrm{F}$ & $\mathrm{C}$ & A & A & A & $\mathrm{T}$ & $\mathrm{T}$ & $\mathrm{C}$ & $\mathrm{C}$ & A & A & A & $\mathrm{T}$ & A & $\mathrm{T}$ & G & A & $\mathrm{T}$ & A & A & A & A & G & $\mathrm{T}$ & A & \\
\hline & coincidence & & $\circ$ & $\circ$ & $\circ$ & $\circ$ & $\circ$ & $\circ$ & & & & & $\circ$ & & $\circ$ & & & & & $\circ$ & & & & $\circ$ & & \\
\hline \multirow[t]{2}{*}{ eve } & $5^{\prime}(-4054) R$ & G & A & A & A & $\mathrm{T}$ & $\mathrm{T}$ & $\mathrm{C}$ & G & A & G & $\mathrm{C}$ & G & G & G & $\mathrm{C}$ & A & A & $\mathrm{T}$ & A & A & A & $\mathrm{C}$ & $\mathrm{T}$ & C & \\
\hline & coincidence & & $\circ$ & $\circ$ & $\circ$ & $\circ$ & $\circ$ & $\circ$ & $\circ$ & & & & & & & & & $\circ$ & & $\circ$ & & & & $\circ$ & & \\
\hline \multirow[t]{2}{*}{ eve } & $5^{\prime}(-2766) R$ & A & A & A & A & $\mathrm{T}$ & $\mathrm{T}$ & $\mathrm{C}$ & $\mathrm{T}$ & $\mathrm{G}$ & $\mathrm{T}$ & $\mathrm{T}$ & G & A & C & $\mathrm{T}$ & $\mathrm{T}$ & G & C & $\mathrm{T}$ & $\mathrm{T}$ & A & A & $\mathrm{T}$ & $\mathrm{T}$ & \\
\hline & coincidence & & o & $\circ$ & $\circ$ & $\circ$ & $\circ$ & o & & & $\circ$ & $\circ$ & & & & & & & & & & & & $\circ$ & & \\
\hline
\end{tabular}

$5^{\prime}(-x x x x) F / R: x x x x$-start position in 5' upstream, F-Forward strand, R-Reverse strand

Table 4(g). Relations between the miRNAs of $g t$ and the 5' upstream region of eve.

\begin{tabular}{|c|c|c|c|c|c|c|c|c|c|c|c|c|c|c|c|c|c|c|c|c|c|c|c|c|c|c|}
\hline gene & miRNA/5'region & 1 & 2 & 3 & 4 & 5 & 6 & 7 & 8 & 9 & 10 & 11 & 12 & 13 & 14 & 15 & 16 & 17 & 18 & 19 & 20 & 21 & 22 & 23 & 24 & 25 \\
\hline eve & dme-miR-315 & $\mathrm{T}$ & $\mathrm{T}$ & $\mathrm{T}$ & $\mathrm{T}$ & $G$ & $A$ & $\mathrm{~T}$ & $\mathrm{~T}$ & G & $\mathrm{T}$ & $T$ & $\mathrm{G}$ & C & $\mathrm{T}$ & $\mathrm{C}$ & $A$ & G & $A$ & $A$ & $A$ & $G$ & $\mathrm{C}$ & & & \\
\hline \multirow[t]{2}{*}{$g t$} & $5^{\prime}(-4685) \mathrm{F}$ & $G$ & $\mathrm{~T}$ & $\mathrm{~T}$ & $\mathrm{~T}$ & G & A & $\mathrm{T}$ & $\mathrm{T}$ & A & $A$ & $\mathrm{C}$ & $\mathrm{T}$ & C & $\mathrm{C}$ & $G$ & $G$ & $A$ & $A$ & $A$ & $A$ & $A$ & $\mathrm{C}$ & & & \\
\hline & coincidence & & $\circ$ & $\circ$ & $\circ$ & $\circ$ & $\circ$ & $\circ$ & $\circ$ & & & & & $\circ$ & & & & & $\circ$ & $\circ$ & $\circ$ & & $\circ$ & & & \\
\hline \multirow[t]{2}{*}{$g t$} & $5^{\prime}(-1674) \mathrm{F}$ & $A$ & $\mathrm{~T}$ & $\mathrm{~T}$ & $\mathrm{~T}$ & G & $A$ & $T$ & $A$ & $A$ & $\mathrm{C}$ & $A$ & $\mathrm{~T}$ & $\mathrm{~T}$ & $\mathrm{~T}$ & $\mathrm{C}$ & $A$ & $G$ & $\mathrm{C}$ & G & $\mathrm{T}$ & $A$ & $A$ & & & \\
\hline & coincidence & & $\circ$ & $\circ$ & $\circ$ & $\circ$ & $\circ$ & $\circ$ & & & & & & & $\circ$ & ० & $\circ$ & o & & & & & & & & \\
\hline \multirow[t]{2}{*}{$g t$} & $5^{\prime}(-946) F$ & $\mathrm{C}$ & $\mathrm{T}$ & $\mathrm{T}$ & $\mathrm{T}$ & G & A & $\mathrm{T}$ & A & $\mathrm{T}$ & G & $\mathrm{C}$ & G & A & A & A & $\mathrm{T}$ & G & $\mathrm{T}$ & $\mathrm{T}$ & $C$ & $\mathrm{~T}$ & A & & & \\
\hline & coincidence & & $\circ$ & $\circ$ & $\circ$ & $\circ$ & $\circ$ & $\circ$ & & & & & $\circ$ & & & & & $\circ$ & & & & & & & & \\
\hline \multirow[t]{2}{*}{$g t$} & $5^{\prime}(-4419) R$ & $\mathrm{~T}$ & $\mathrm{~T}$ & $\mathrm{~T}$ & $\mathrm{~T}$ & G & A & $\mathrm{T}$ & G & A & $A$ & C & $\mathrm{T}$ & $\mathrm{G}$ & $\mathrm{T}$ & $\mathrm{C}$ & $A$ & $A$ & $\mathrm{C}$ & $\mathrm{G}$ & $\mathrm{T}$ & $\mathrm{T}$ & $\mathrm{T}$ & & & \\
\hline & coincidence & $\circ$ & $\circ$ & $\circ$ & $\circ$ & $\circ$ & $\circ$ & $\circ$ & & & & & & & $\circ$ & $\circ$ & $\circ$ & & & & & & & & & \\
\hline \multirow[t]{2}{*}{$g t$} & $5^{\prime}(-3638) R$ & $\mathrm{~T}$ & $\mathrm{~T}$ & $\mathrm{~T}$ & $\mathrm{~T}$ & G & A & $\mathrm{T}$ & $\mathrm{T}$ & A & $\mathrm{C}$ & C & $\mathrm{C}$ & $A$ & $A$ & $A$ & $\mathrm{~T}$ & G & $A$ & $\mathrm{C}$ & $A$ & $\mathrm{~T}$ & $\mathrm{~T}$ & & & \\
\hline & coincidence & $\circ$ & $\circ$ & $\circ$ & $\circ$ & $\circ$ & $\circ$ & $\circ$ & $\circ$ & & & & & & & & & $\circ$ & $\circ$ & & ० & & & & & \\
\hline \multirow[t]{2}{*}{$g t$} & $5^{\prime}(-1330) R$ & $A$ & $\mathrm{~T}$ & $T$ & $\mathrm{~T}$ & $G$ & $A$ & $\mathrm{~T}$ & $\mathrm{~T}$ & C & $A$ & $T$ & $\mathrm{G}$ & $A$ & $\mathrm{C}$ & $G$ & $C$ & $C$ & $\mathrm{G}$ & $\mathrm{C}$ & $\mathrm{C}$ & $A$ & $G$ & & & \\
\hline & coincidence & & $\circ$ & $\circ$ & $\circ$ & $\circ$ & $\circ$ & $\circ$ & $\circ$ & & & $\circ$ & $\circ$ & & & & & & & & & & & & & \\
\hline \multirow[t]{2}{*}{$g t$} & $5^{\prime}(-710) R$ & A & $\mathrm{T}$ & $\mathrm{T}$ & $\mathrm{T}$ & G & A & $\mathrm{T}$ & $\mathrm{T}$ & $\mathrm{T}$ & $\mathrm{T}$ & $\mathrm{T}$ & $\mathrm{T}$ & $A$ & $\mathrm{~T}$ & $\mathrm{~T}$ & $A$ & C & $A$ & $A$ & $\mathrm{~T}$ & $\mathrm{~T}$ & $\mathrm{G}$ & & & \\
\hline & coincidence & & $\circ$ & $\circ$ & $\circ$ & $\circ$ & $\circ$ & $\circ$ & $\circ$ & & $\circ$ & $\circ$ & & & $\circ$ & & $\circ$ & & $\circ$ & $\circ$ & & & & & & \\
\hline
\end{tabular}

$5^{\prime}(-x x x x) F / R$ : xxxx-start position in 5' upstream, F-Forward strand, R-Reverse strand

Table 4(h). Relations between the miRNAs of eve and the 5' upstream region of gt. 
by binding the common sequences listed in Tables $4 \mathrm{~g}$ and $4 \mathrm{~h}$. Possible regulatory sequences involved in the interaction between eve and $b c d$, $h b, K r$, and $g t$ are shown in Figure 5.

\section{Relations between consensus sequences of individual miRNAs and random sequences}

The relations between frequency probabilities of the consensus sequences described and random sequences of the same length were examined in the range from -1 to -5000 of the 5 ' upstream region. Generally, the probability of the frequency of any specific $n$-nucleotide sequence for individual miRNAs is obtained as follows:

$$
\boldsymbol{P}_{n}=\frac{1}{4^{n}}
$$

On the other hand, the probability of the consistency between the sequence of $n$ random nucleotides and the sequence of the 5' upstream region $(-1$ to -5000$)$ of target genes is computed as follows:

$$
P_{n r}=\left(\frac{1}{4^{n}}\right) \times\left(\frac{5000 \times 2}{4^{n}}\right)
$$

Where the factor 2 accounts for the possibility of the consistent sequence being in either the forward or reverse strand.

Therefore, the ratio of the frequency of any specific $n$-nucleotide sequence for individual miRNAs to $n$ random nucleotide frequency in the restricted 5' upstream region ( -1 to -5000$)$ can be expressed using the ratio of $\boldsymbol{P}_{n}$ and $\boldsymbol{P}_{n r}$ as follows:

$$
R=\left(\frac{P_{n}}{P_{n r}}\right)^{n} \times r_{p}=\left(\frac{4^{n}}{10000}\right) \times r_{p}
$$

where $\boldsymbol{r}_{p}$ is the number of same-length consensus sequences.

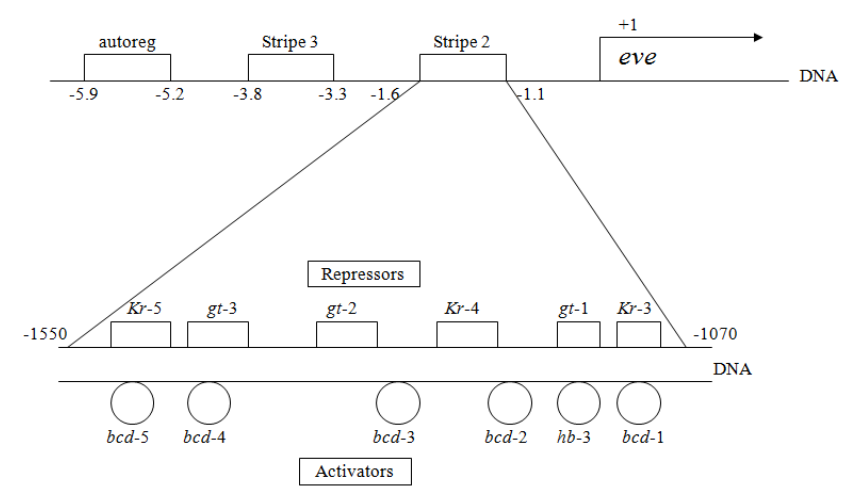

Figure 4: Repressors and activators of eve stripe 2. "autoreg" is an autoregulatory element required for the refinement and maintenance of the eve expression pattern during gastrulation and germ band elongation.

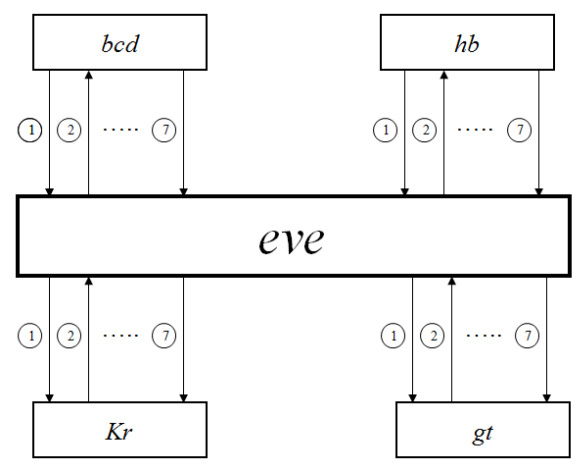

Figure 5: Regulatory sequences that might be involved in the interaction between eve and $b c d, h b, K r$ and $g t$.
$R \geq 1$ indicates that in the 5' upstream range from -1 to -5000 the probability of the consistency of the miRNAs is higher than that of random nucleotide sequences of the same lengths. That is, consistencies between the sequence of some nucleotides in individual miRNAs and the sequence in the 5' upstream regions of target genes are more frequent than are consistencies between random sequences and the sequence in the 5 ' upstream regions. $R<1$, on the other hand, means that the probability of the consistency of the miRNAs is lower than that of random nucleotide sequences.

The relations between the miRNAs of $b c d$ and $h b$ and the 5' upstream regions of $h b$ and $b c d$ are listed in Table $5 \mathrm{a}$. In case of the miRNAs of $b c d$ and the 5 ' upstream region of $h b$, as there are four consistent six-nucleotide sequences for dme-miR-79 listed in Table $2 \mathrm{a}, \boldsymbol{R}$ is computed as 1.64 by using equation (3). This indicates that the probability of consistency for the miRNAs is 1.64 times greater than it is for sequences with random nucleotide frequencies. For dme-miR-4, 286, 279, 996, 999, 315, 1000, 283, 989, 1017, individual $R$ s are also computed as listed in (Table 5a). Similarly, in case of the miRNAs of $h b$ and the 5' upstream region of $b c d$, the $R$ values obtained as for dme-miR-989, 963, 927, 8, and 315 are respectively $1.1,1.1,0.55,4.42,2.2,8.84$ and 1.65 (Table 5a). The sum of individual $R$ s for the relations between miRNAs of $b c d / h b$ and 5' upstream of $h b / b c d$ are respectively 36.4 and 19.9 listed in Table 5a. These results therefore imply that the probabilities of consistencies for the miRNAs are greater than those of consistencies for sequences with random nucleotide frequencies.

The relations between the miRNAs of $b c d / e v e, h b / e v e, K r / e v e$, and $g t / e v e$ and the 5' upstream regions of eve/bcd, eve/hb, eve/Kr, and eve/gt are listed in Table $5 \mathrm{~b}$. All these results also indicate that the probabilities of consistencies for the miRNAs are greater than those for same-length sequences with random nucleotide frequencies. This implies that miRNAs play regulatory roles in the 5 ' upstream regions of genes.

As the proposed miRNA mediations between genes are based on the consistencies between individual miRNAs and 5' upstream regions, it is necessary to confirm whether these miRNAs are expressed experimentally in the early embryonic development of $D$. melanogaster.

\section{Conclusions}

This paper analyzed the relations between the miRNA nucleotide sequences of $b c d, h b$, eve, $K r$ and $g t$ and the sequences in the 5' upstream regions of these genes. As a result, there were many consensus sequences between the sequences of individual miRNAs and the sequences in the 5' upstream regions of these genes. Based on these results, the paper proposed that miRNA mediates inquiries and responses in regulatory interactions between genes. This paper also analyzed the relations between the frequency probabilities of miRNA consensus sequences and random sequences in the 5' upstream region of the target genes and showed that the probabilities of consistencies between individual miRNAs and 5' upstream regions are greater than those expected for same-length sequences with random nucleotide frequencies. These results thus imply that some miRNAs are closely related to the 5 ' upstream regions of certain genes and play important roles in the regulation of gene expression during the embryonic development of $D$. melanogaster. 
Citation: Takasaki S (2013) Roles of miRNAs in Early Embryonic Development of Drosophila melanogaster. Genetics 2: 122. doi:10.4172/21611041.1000122

Page 13 of 14

\begin{tabular}{|c|c|c|c|c|c|c|c|}
\hline \multirow{2}{*}{ base gene/regulated gene } & mi RNA & \multirow{2}{*}{ length (nt) } & \multirow[b]{2}{*}{$r_{p}$} & \multirow[b]{2}{*}{$P_{n}$} & \multirow{2}{*}{$P_{n r}$} & \multirow{2}{*}{$R$} & \multirow{2}{*}{ Sum } \\
\hline & Locus of $5^{\prime}$ & & & & & & \\
\hline & miR-79 & \multirow{2}{*}{6} & \multirow{5}{*}{4} & \multirow{5}{*}{$(1 / 4096)^{\star} 4$} & \multirow{5}{*}{$\begin{array}{c}(1 / 4096)^{\star} \\
(10000 / 4096)\end{array}$} & \multirow{5}{*}{1.64} & \\
\hline & -4333 & & & & & & \\
\hline & -3078 & 6 & & & & & \\
\hline & -4326 & 6 & & & & & \\
\hline & -3071 & 6 & & & & & \\
\hline & $\operatorname{miR}-4$ & \multirow{2}{*}{6} & 1 & \multirow{2}{*}{$1 / 4096$} & $(1 / 4096)^{*} 2$ & \multirow{2}{*}{0.41} & \\
\hline & -4284 & & 1 & & $(10000 / 4096)$ & & \\
\hline & miR-286 & 6 & 1 & $1 / 4096$ & $(1 / 4096)^{\star}$ & 041 & \\
\hline & -1576 & b & 1 & $1 / 4096$ & $(10000 / 4096)$ & 0.41 & \\
\hline & miR-279 & 6 & 1 & $1 / 4096$ & $(1 / 4096)^{*}$ & 0.41 & \\
\hline & -1577 & 0 & 1 & $1 / 4090$ & $(10000 / 4096)$ & 0.41 & \\
\hline & miR-996 & 6 & 1 & $1 / 4096$ & $(1 / 4096)^{*}$ & 0.41 & \\
\hline & -1577 & 6 & 1 & $1 / 4096$ & $(10000 / 4096)$ & 0.41 & \\
\hline & miR-999 & 8 & 1 & $1 / 65536$ & $(1 / 65536)^{*}$ & 653 & \\
\hline & -4308 & 0 & 1 & 1/05030 & $(10000 / 65536)$ & 0.53 & \\
\hline & miR-315 & 7 & & & & & \\
\hline & -916 & & 2 & $(1 / 16384)^{\star} 2$ & $\begin{array}{c}(1 / 16384)^{*} \\
(10000 / 16384)\end{array}$ & 3.28 & \\
\hline & -3577 & 7 & & & & & \\
\hline & miR-1000 & 6 & & & & & \\
\hline & -4657 & 0 & 2 & $(1 / 1024)^{\star} 2$ & $\begin{array}{c}(1 / 1024)^{x} \\
(10000 / 1024)\end{array}$ & 0.82 & \\
\hline & -1192 & 6 & & & & & \\
\hline & -296 & 7 & 2 & $(1 / 16384)^{*} 2$ & $(1 / 16384)^{*}$ & 328 & \\
\hline & -2533 & 7 & 2 & $(1 / 10004) 2$ & $(10000 / 16384)$ & $0 . \angle 0$ & \\
\hline & miR-283 & 6 & & & & & \\
\hline & -1019 & 0 & 3 & $(1 / 4096)^{*} 3$ & $(1 / 4096)^{\star}$ & 123 & \\
\hline & -2531 & 6 & 3 & (1/4090 3 & $(10000 / 4096)$ & & \\
\hline & -1767 & 6 & & & & & \\
\hline & -1283 & 7 & & & & & \\
\hline & -1258 & 7 & & & & & \\
\hline & -1917 & 7 & 5 & $(1 / 16384)^{\star} 5$ & $\begin{array}{c}(1 / 16384)^{x} \\
(10000 / 16384)\end{array}$ & 8.2 & \\
\hline & -1179 & 7 & & & & & \\
\hline & -1092 & 7 & & & & & \\
\hline $\mathrm{bcd} / \mathrm{hd}$ & -1630 & 8 & 1 & $1 / 65536$ & $\begin{array}{c}(1 / 65536)^{*} \\
(10000 / 65536)\end{array}$ & 6.53 & \\
\hline & miR-989 & 6 & 1 & $1 / 4096$ & $(1 / 4096)^{*}$ & 0.41 & \\
\hline & -2869 & & & & $(10000 / 4096)$ & & 36.4 \\
\hline & miR-1017 & 6 & & & & & \\
\hline & -4333 & 6 & 3 & $(1 / 4096)^{* 3}$ & $(1 / 4096)^{\star}$ & 123 & \\
\hline & -3078 & 6 & & 0 (1/4000 & $(10000 / 4096)$ & & \\
\hline & -4326 & 6 & & & & & \\
\hline & -3070 & 7 & 1 & $1 / 16384$ & $\begin{array}{c}(1 / 16384)^{\star} \\
(10000 / 16384)\end{array}$ & 1.64 & \\
\hline & miR-989 & 6 & & & & & \\
\hline & -3194 & 6 & 2 & $(1 / 4096)^{\star} 2$ & $\begin{array}{c}(1 / 4096)^{x} \\
\left(3708^{*} 2 / 4096\right)\end{array}$ & 1.1 & \\
\hline & -2445 & 6 & & & & & \\
\hline & miR-963 & 6 & & & & & \\
\hline & -3005 & 0 & 2 & $(1 / 4096)^{\star} 2$ & $\begin{array}{c}(1 / 4096)^{\times} \\
\left(3708^{*} 2 / 4096\right)\end{array}$ & 1.1 & \\
\hline & -2191 & 6 & & & & & \\
\hline & miR-927 & 6 & 1 & $1 / 4096$ & $(1 / 4096)^{*}$ & 0.55 & \\
\hline & -989 & 0 & 1 & $1 / 4090$ & $\left(3708^{*} 2 / 4096\right)$ & 0.55 & \\
\hline & -487 & 7 & 2 & $(1 / 16384)^{*} ?$ & $(1 / 16384)^{*}$ & 442 & \\
\hline & -1646 & 7 & 2 & $(1 / 10004) 2$ & $\left(3708^{\star} 2 / 16384\right)$ & 4.42 & \\
\hline & miR-8 & 7 & 1 & $1 / 16384$ & $(1 / 16384)^{*}$ & 221 & \\
\hline & -2925 & $t$ & 1 & $1 / 10384$ & $\left(3708^{\star} 2 / 16384\right)$ & 2.21 & \\
\hline$h b / b c d$ & -3597 & 8 & 1 & $1 / 65536$ & $\begin{array}{c}(1 / 65536)^{\star} \\
\left(3708^{\star} 2 / 65536\right)\end{array}$ & 8.84 & 19.9 \\
\hline & miR-315 & & & & & & \\
\hline & -2698 & 6 & 3 & $(1 / 4096)^{* 3}$ & $(1 / 4096)^{*}$ & 165 & \\
\hline & -3645 & 6 & 3 & $(1 / 4096) 3$ & $\left(3708^{\star} 2 / 4096\right)$ & 1.65 & \\
\hline & -2140 & 6 & & & & & \\
\hline
\end{tabular}

Note: The maximum of 5 ' upstream region of $b c d$ is -3708 .

Table 5(a). Relations between the miRNAs of $b c d / h b$ and the $5^{\prime}$ upstream region of $h b / b c d$ 
Citation: Takasaki S (2013) Roles of miRNAs in Early Embryonic Development of Drosophila melanogaster. Genetics 2: 122. doi:10.4172/21611041.1000122

Page 14 of 14

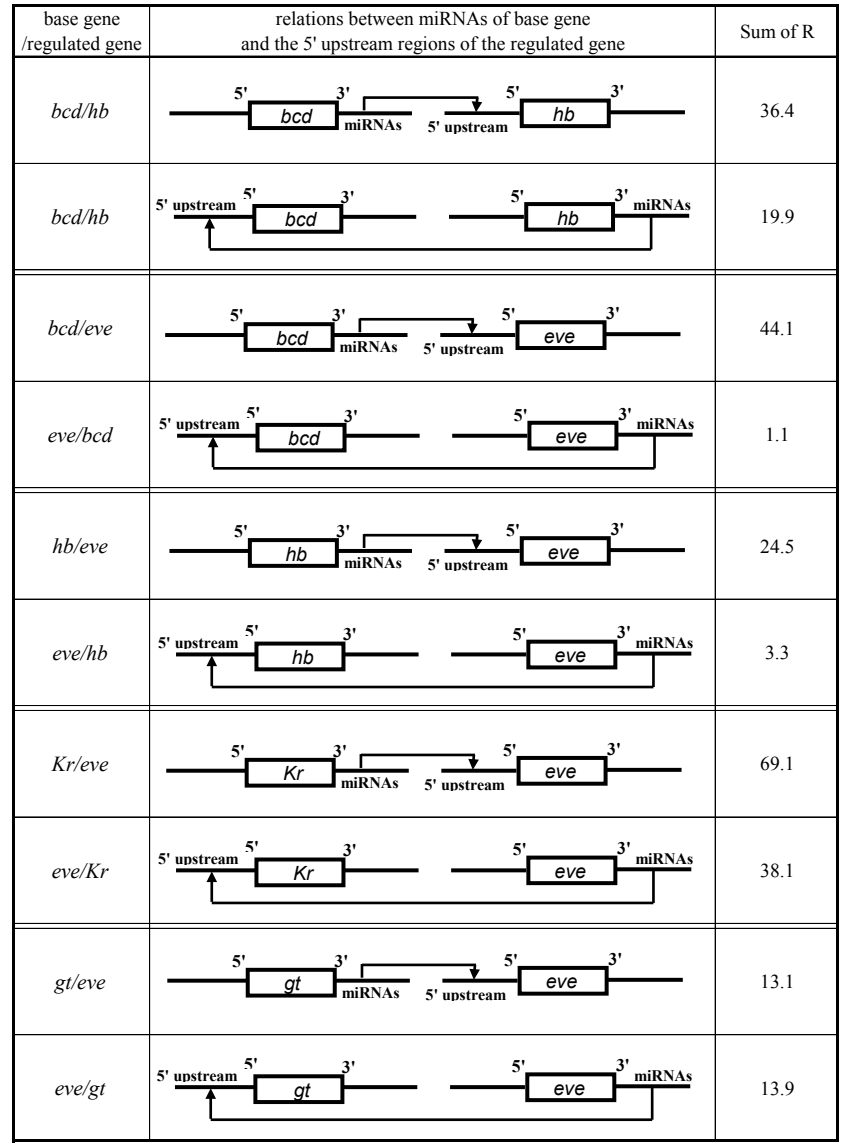

Table 5(b). Relations between the miRNAs of base genes and the $5^{\prime}$ upstream region of regulated genes.

\section{References}

1. Aravin AA, Lagos-Quintana M, Yalcin A, Zavolan M, Marks D, et al. (2003) The small RNA profile during Drosophila melanogaster development. Dev Cell 5: 337-350.

2. Bartel DP (2004) MicroRNAs: genomics, biogenesis, mechanism, and function Cell 116: 281-297.

3. Doench JG, Sharp PA (2004) Specificity of microRNA target selection in translational repression. Genes Dev 18: 504-511.

4. Lai EC (2002) Micro RNAs are complementary to 3' UTR sequence motifs that mediate negative post-transcriptional regulation. Nat Genet 30: 363-364.

5. Lee RC, Feinbaum RL, Ambros V (1993) The C. elegans heterochronic gene lin-4 encodes small RNAs with antisense complementarity to lin-14. Cell 75: 843-854.

6. Wightman B, Ha I, Ruvkun G (1993) Posttranscriptional regulation of the heterochronic gene lin-14 by lin- 4 mediates temporal pattern formation in C. elegans. Cell 75: 855-862.

7. Enright AJ, John B, Gaul U, Tuschl T, Sander C, et al. (2003) MicroRNA targets in Drosophila. Genome Biol 5: R1.

8. Stark A, Brennecke J, Russell RB, Cohen SM (2003) Identification of Drosophila MicroRNA targets. PLoS Biol 1: E60.

9. Gesellchen V, Boutros M (2004) Managing the genome: microRNAs in Drosophila. Differentiation 72: 74-80.

10. Biemar F, Zinzen R, Ronshaugen M, Sementchenko V, Manak JR, et al. (2005) Spatial regulation of microRNA gene expression in the Drosophila embryo. Proc Natl Acad Sci U S A 102: 15907-15911.

11. Aboobaker AA, Tomancak P, Patel N, Rubin GM, Lai EC (2005) Drosophila microRNAs exhibit diverse spatial expression patterns during embryonic development. Proc Natl Acad Sci U S A 102: 18017-18022.
12. Bentwich I (2005) Prediction and validation of microRNAs and their targets. FEBS Lett 579: 5904-5910.

13. Wienholds E, Plasterk RH (2005) MicroRNA function in animal development FEBS Lett 579: 5911-5922.

14. Robins H, Li Y, Padgett RW (2005) Incorporating structure to predict microRNA targets. Proc Natl Acad Sci U S A 102: 4006-4009.

15. Lai EC, Tam B, Rubin GM (2005) Pervasive regulation of Drosophila Notch target genes by GY-box-, Brd-box-, and K-box-class microRNAs. Genes Dev 19: $1067-1080$.

16. Bartel DP (2009) MicroRNAs: target recognition and regulatory functions. Cell 136: 215-233.

17. Carthew RW, Sontheimer EJ (2009) Origins and Mechanisms of miRNAs and siRNAs. Cell 136: 642-655.

18. Driever W, Nüsslein-Volhard C (1989) The bicoid protein is a positive regulator of hunchback transcription in the early Drosophila embryo. Nature 337: 138143

19. Driever W, Thoma G, Nüsslein-Volhard C (1989) Determination of spatia domains of zygotic gene expression in the Drosophila embryo by the affinity of binding sites for the bicoid morphogen. Nature 340: 363-367.

20. Struhl G, Struhl K, Macdonald PM (1989) The gradient morphogen bicoid is a concentration-dependent transcriptional activator. Cell 57: 1259-1273.

21. Hanes SD, Brent R (1991) A genetic model for interaction of the homeodomain recognition helix with DNA. Science 251: 426-430.

22. St Johnston D, Nüsslein-Volhard C (1992) The origin of pattern and polarity in the Drosophila embryo. Cell 68: 201-219.

23. Small S, Blair A, Levine M (1992) Regulation of even-skipped stripe 2 in the Drosophila embryo. EMBO J 11: 4047-4057.

24. Small S, Blair A, Levine M (1996) Regulation of two pair-rule stripes by a single enhancer in the Drosophila embryo. Dev Biol 175: 314-324.

25. Burz DS, Rivera-Pomar R, Jäckle H, Hanes SD (1998) Cooperative DNAbinding by Bicoid provides a mechanism for threshold-dependent gene activation in the Drosophila embryo. EMBO J 17: 5998-6009.

26. Crauk O, Dostatni N (2005) Bicoid determines sharp and precise target gene expression in the Drosophila embryo. Curr Biol 15: 1888-1898.

27. Xie X, Lu J, Kulbokas EJ, Golub TR, Mootha V, et al. (2005) Systematic discovery of regulatory motifs in human promoters and 3' UTRs by comparison of several mammals. Nature 434: 338-345.

28. Hobert O (2004) Common logic of transcription factor and microRNA action Trends Biochem Sci 29: 462-468.

29. Griffiths-Jones S, Grocock RJ, van Dongen S, Bateman A, Enright AJ (2006) miRBase: microRNA sequences, targets and gene nomenclature. Nucleic Acids Res 34: D140-144.

30. Kozomara A, Griffiths-Jones S (2011) miRBase: integrating microRNA annotation and deep-sequencing data. Nucleic Acids Res 39: D152-157.

31. van Helden J (2003) Regulatory sequence analysis tools. Nucleic Acids Res 31: 3593-3596.

32. Bergman CM, Carlson JW, Celniker SE (2005) Drosophila DNase I footprint database: a systematic genome annotation of transcription factor binding sites in the fruitfly, Drosophila melanogaster. Bioinformatics 21: 1747-1749. 